Article

\title{
The In-Situ Quantification of Structural Radiation Damage in Zircon Using Laser-Induced Confocal Photoluminescence Spectroscopy
}

\author{
Christoph Lenz ${ }^{1,2,3, *\left(\mathbb{D}, \text { Elena Belousova }^{3}(\mathbb{D} \text { and Gregory R. Lumpkin }\right.}{ }^{1}$ \\ 1 Australian Nuclear Science and Technology Organisation, Lucas Heights, Sydney, NSW 2234, Australia; \\ grl@ansto.gov.au \\ 2 Institut für Mineralogie und Kristallographie, Universität Wien, 1090 Vienna, Austria \\ 3 Australian Research Council (ARC) Centre of Excellence for Core to Crust Fluid Systems (CCFS) and \\ National Key Centre for Geochemical Evolution and Metallogeny of Continents (GEMOC), Department of \\ Earth and Environmental Sciences, Macquarie University, Sydney, NSW 2109, Australia; \\ elena.belousova@mq.edu.au \\ * Correspondence: christoph.lenz@univie.ac.at
}

Received: 11 December 2019; Accepted: 8 January 2020; Published: 20 January 2020

\begin{abstract}
We present a new methodology for laser-induced steady-state photoluminescence (PL) spectroscopy of $D y^{3+}$ that aims at a direct quantification of the amorphous fraction $f_{\text {a }}$ present in zircon $\left(\mathrm{ZrSiO}_{4}\right)$, which undergoes a transition from a crystalline to a metamict state due to cumulative self-irradiation damage caused by the radioactive decay of substituted $U$ and $T h$. Using state-of-the-art confocal spectrometers attached to optical microscopes, measurements may be performed non-destructively on the micrometre length-scale with the option to visualize radiation-damage patterns as revealed by hyperspectral PL maps. Zircon from the Ratnapura district (Sri Lanka, $520 \mathrm{Ma}$ ), was used as reference material to substantiate the applicability of the proposed method. The accumulation of radiation damage in this material was investigated in detail and obtained $f_{\mathrm{a}}$ values correlate with calculated $\alpha$-doses in accordance to the direct impact model reported variously in the literature. The impact of chemically-induced, heterogeneous broadening of Raman and $\mathrm{Dy}^{3+}$ emission spectral bands is discussed on two examples from Mt. Malosa district, Malawi. A mean weighted U-Pb isotope age of $111 \pm 1 \mathrm{Ma}$ (pegmatitic-type) and a discordia age of $112 \pm 1.6 \mathrm{Ma}$ (hydrothermal-type) as obtained by LA-ICP-MS confirm their close genetic and temporal relationship. Studied zircon examples demonstrate that the amount of radiation damage present may have a substantial effect on the precision of LA-ICP-MS ages, but cannot be considered an exclusive cause for bias of obtained isotope ages.
\end{abstract}

Keywords: photoluminescence spectroscopy; REE; confocal hyperspectral mapping; zircon $\mathrm{ZrSiO}_{4}$; radiation damage; amorphous fraction; quantification; Raman; LA-ICP-MS; isotope age bias

\section{Introduction}

The transformation of an initially crystalline material into an amorphous state due to corpuscular irradiation is commonly referred to as "amorphisation" or "metamictisation" [1-3]. In nature, the accumulation of self-irradiation induced structural damage is created mainly during $\alpha$-decay events in the ${ }^{232} \mathrm{Th},{ }^{235} \mathrm{U}$, and ${ }^{238} \mathrm{U}$ decay chains, by the nuclear interaction (atomic "knock-ons") of recoiled heavy daughter [4,5]. Many accessory minerals, including zircon $\left(\mathrm{ZrSiO}_{4}\right)$, incorporate variable amounts of actinides, whose radioactive decay creates structural disorder in their crystal structure over geological periods of time. In zircon this causes changes of its physical and solid-state properties such as refraction and birefringence, hardness, density, and elastic moduli [6-9], and a general decrease of 
the chemical resistance [10-12]. The generally increased susceptibility of radiation-damaged zircon to chemical alteration is of enormous importance, as these processes may negatively affect the ability of the mineral to retain radiogenic nuclei and therefore bias results of chemical and isotopic age determination applied in U-Pb geochronology [13-15]. Moreover, the investigation of gradually radiation damaged and metamict minerals, and their synthetic analogues, has increased appreciably over the past decades, stimulated by the potential use of mineral-like ceramics as waste forms for the immobilisation of reprocessed spent nuclear fuel and other radioactive waste [16,17]. Information obtained from studies on radiation-damage-assisted alteration in accessory minerals has important implications for the validation of the long-term performance of nuclear waste forms for the disposal in geological repositories, as radiation damage negatively affects the ability of analogue ceramics to immobilise incorporated radionuclides, e.g., $\mathrm{Pu}, \mathrm{Am}, \mathrm{U}$ and Th [18,19].

One of the major problems in the evaluation of effects caused by radiation-damage is the accurate quantification of the latter; i.e., the estimation of the fraction of the crystal structure which has been amorphised by self-irradiation. Since the early study by Holland and Gottfried [6], changes in zircon birefringence has been used to visualize and estimate the radiation damage in complexly zoned zircon [8,20-23]. Electron microscopic techniques, such as scanning electron microscopy and transmission electron microscopy are applied frequently to visualize radiation damage in various materials [24-32]. Those techniques, however, are mostly of qualitative nature and not appropriate to quantify the amorphous component. For the latter, different $X$-ray diffraction methods $[4,26,33,34]$ and several spectroscopic techniques have been developed. For instance, Zhang and Salje [35] used infrared-absorption spectroscopy, and Farnan and Salje [36] applied ${ }^{29}$ Si nuclear magnetic-resonance spectroscopy to directly determine the amorphous fraction $f_{\mathrm{a}}$ in radiation-damaged zircon. The major disadvantage of the latter techniques is that all of them probe bulk material, i.e., a few milligram of powdered or entire monolithic zircon crystals have been used, respectively. The samples to be analysed, hence, need to meet certain pre-conditions which include: (i) a sufficient amount of material available and (ii) an adequate chemical homogeneity to ensure that radiation damage has been accumulated homogeneously within the sample over geological periods of time. This is the major reason why those studies took advantage of relatively large, gem-quality zircon samples from gem-gravels in Ratnapura, Sri Lanka that have high chemical homogeneity. For the same reason, zircon samples from this location are thoroughly studied also with respect to their use as reference material in U-Pb geochronology (e.g., SL7: Kinny et al. [37]; CZ3: Pidgeon et al. [38]; M257: Nasdala et al. [39]; M127: Nasdala et al. [40]; BR266: Stern [41]; BB: Santos et al. [42]).

To estimate the degree of radiation-induced structural disorder in complexly zoned zircon on the $\mu \mathrm{m}$-scale, Raman spectroscopy has been introduced by Nasdala et al. [22,43] using the band width of the symmetric stretching vibration $\mathrm{B}_{1 \mathrm{~g}}\left(v_{3}\right)$ of zircon's $\mathrm{SiO}_{4}$ tetrahedrally-coordinated anionic complex. Confocal photoluminescence (PL) spectroscopy of rare-earth elements (REE) has been introduced recently for the same purpose [44,45]. Trivalent REEs are common trace elements in zircon and many other accessory minerals, and are found in close geochemical relationship to the actinides $U$ and Th due to their similar ionic radii and high valences [46]. The luminescence of REEs is excited most efficiently using appropriate light or laser sources [47-51] and is further known to have unique spectroscopic characteristics due to their shielded electronic intra $f-f$ transitions (see detailed discussion in Lenz et al. [52]). Emissions arising from those transitions consist of several narrow sublevel-bands ("Stark levels") that strongly depend on the local structural environment the specific REE ion is incorporated in, and hence, may be used as site-specific structural probe. Very similar to the Raman spectroscopic approach, the band widths of narrow PL bands of REEs have been used as a measure of irradiation-induced structural disorder (i.e., $D y^{3+}$ and $\mathrm{Nd}^{3+}$ in zircon; cf., [44]). A major challenge for using linewidths of Raman or PL signals for a quantitative measure of radiation effects is its calibration using reference samples of known amorphous fraction $f_{\mathrm{a}}$ or equivalent effective $\alpha$-dose (for zircon see Palenik et al. [8]). Calibrations based on the $\alpha$-dose, which is the theoretical number of $\alpha$-events calculated from the concentration of $U$ and $T h$, their half-life and the geological 
age of the sample [6], are often biased because of the insufficient knowledge of the samples thermal and, hence, annealing history (see the detailed discussion in Nasdala et al. [22]).

In addition, several Raman spectroscopic studies on zircon have revealed that Raman band widths occasionally may be affected strongly by the substitution and presence of extensive amounts of non-formula elements. Such examples comprise high-U zircon of the "Chernobyl lava" [53] and other U-rich samples [54,55], as well as hydrothermal zircon from the Mt. Malosa Massif (Malawi), that is characterised by extremely high concentrations of REEs [56]. This chemically-induced effect may be critical only for a few examples of zircon that grew in late-stage magmatic to hydrothermal environments, but have been documented to be important for other mineral systems that show higher chemical flexibility than zircon (e.g., monazite-type group minerals as reported by Ruschel et al. [57]).

In this study, we tested a new approach presented by Lenz et al. [58] that aims at a direct determination of the amorphous fraction $f_{\mathrm{a}}$ from in-situ confocal PL measurements without the need for an indirect correlation via spectral band-widths. This methodology has been developed for artificially heavy-ion irradiated orthophosphate ceramics that showed a rather complex, non-linear band-width broadening upon damage accumulation [58]. Here, we demonstrate the applicability of this approach to naturally self-irradiation damaged zircon using well-studied reference material from the Ratnapura district (Sri Lanka). The basic principle and underlying interpretation of spectral PL data for a visualization of the amorphous fraction $f_{\mathrm{a}}$ in hyperspectral maps are demonstrated in detail.

\section{Materials and Methods}

\subsection{Samples}

Previous studies on zircon samples from Sri Lanka have investigated the correlation between the accumulated amorphous fraction $f_{\mathrm{a}}$ versus the calculated $\alpha$-dose in very detail $[33,35,36]$. Consequently, we tested our PL methodology with samples from this location. Various gem-quality, homogeneous single crystals (see Table A1) and two brownish, non-transparent, large, $\mathrm{cm}$-sized, but heterogeneously zoned, single crystals were investigated in detail (SL1-minID: P3H-LYV; SL2-minID: 4TL-XKA; see Table A2). The Sri Lankan zircon samples stem from well-known gemstone placers located in the central Sri Lankan granulite belt in the Ratnapura district. Zircon from the Ratnapura district are discussed to originate from granitoid pegmatites that have intruded into Al-rich sediments, but the original location of its source rocks is unknown [25].

In this study, we also included large, heterogeneous zircon crystals from a granitic, alkaline pegmatite near Mt. Malosa, located within the Zomba-Malosa Complex of the Chilwa Alkaline Province in Malawi, Africa. Pegmatites of this region have undergone multiple late-stage hydrothermal alteration and are characterised by unique mineral composition including aegirine, arfvedsonite, fluorite, Ca-REE-fluorocarbonates, $\mathrm{Nb}$-Ta-Y oxides in large miarolitic cavities with $\mathrm{Na}$-Be-silicates, xenotime-(Y), as well as zircon [56,59]. Three morphological types of zircon from this location have been distinguished [56]: (1) translucent reddish-brownish crystals, (2) opaque short prismatic brownish zircon and (3) translucent prismatic yellow crystals. We have studied zircon samples of type 2 (sample MalawiX-minID: GJ0-32C) and type 3 (MalawiA-minID: 8DE-AE0).

Following the approach of Nasdala et al. [60], the studied large, heterogeneous single-crystals were cut in half using a diamond-tipped stainless-steel wire saw (WELL Diamond Saw 3032; Ø $300 \mu \mathrm{m}$ effective cutting). One half was subjected to heat treatment in furnace at $\sim 1300^{\circ} \mathrm{C}$ for 3 days, whereas the other half remained untreated. Both halves were then embedded in one epoxy mount in close proximity, and gently polished. This preparation procedure was chosen to obtain sample mounts for direct comparison of two halves of one initial crystal which are widely similar in terms of their internal textures and chemical compositions, but significantly different in terms of their structural state. Note that one half is still in its natural, potentially radiation-damaged state, whereas its counterpart has undergone complete structural reconstitution. 


\subsection{Photoluminescence and Raman Spectroscopy}

A confocal, dispersive LabRam Evolution HR800 spectrometer (HorIBA, Kyoto, Japan) was used for Raman and laser-induced steady-state photoluminescence (PL) spectroscopic measurements. The spectrometer is equipped with a Si-based, Peltier-cooled charge-coupled device (CCD) detector and coupled to an Olympus BX41 optical microscope with a confocal hole in the analysing beam path achieving a maximum spatial resolution of $\sim 1 \mu \mathrm{m}$ lateral and $\sim 2-3 \mu \mathrm{m}$ in depth using a $100 \times$ objective (Olympus MplanN, NA = 0.9). We used a $473 \mathrm{~nm}$ diode-pumped solid-state laser with the beam path aligned through the microscope objective (quasi-backscattering configuration) to directly excite the most prominent luminescence emission in zircon (e.g., $D y^{3+}$, Figure 1a; see details in [44]). Raman measurements were performed using the $633 \mathrm{~nm}$ emission of a He-Ne gas laser. Laser power was adjusted to not exceed ca. $8-15 \mathrm{~mW}$ at the sample surface. PL measurements were performed using a 600 lines per millimetre $(1 / \mathrm{mm})$ grating that achieves a spectral resolution of ca. $2.5 \mathrm{~cm}^{-1}$ (in the blue to yellow spectral range of the main Dy emissions). High-resolution Raman spectra were recorded using a $1800 \mathrm{l} / \mathrm{mm}$ grating with a resolution of $0.8 \mathrm{~cm}^{-1}$ in the red spectral range. Spectral calibration of the spectrometer system was done using the $633 \mathrm{~nm}$ He-Ne laser Rayleigh peak, and its accuracy cross-checked regularly using neon-krypton lamp emissions in the respective wavelength ranges. Peak positions are reproducible within $\pm 1.5 \mathrm{~cm}^{-1}$.

Raman bands were background-corrected and fitted using Gauss-Lorentz (pseudo-Voigt) functions. Note that for some samples (e.g., sample MalawiA) a two-fold Gauss-Lorentz function was used to account for strongly asymmetric band shapes. Obtained full-widths at half-maxima (FWHM) were corrected for the system's spectral resolution according to Váczi [61].

Photoluminescence hyperspectral maps were built from raster of point measurements obtained with the help of a coupled, software-controlled MärzHAUsER x-y-z mechanical stage. Due to cm-sized dimensions of samples studied here, a somewhat lower spatial resolution of a long-distance $50 \times$ objective (OLympus LMPlanFLN, NA = 0.5) was accepted for comparably large hyperspectral maps. Data reduction and treatment for each measurement spot was done using a software-based, automated procedure that is described in more detail below (see Results and Discussion).

\subsection{Trace-Element Analyses and U-Pb Geochronology}

Trace-element (TE) concentrations and isotopic ratios for $\mathrm{U}-\mathrm{Pb}$ age determination of various measurement spots on the large zircon crystals SL1, SL2, MalawiX and MalawiA were obtained using an AgILEnt 7700 quadrupole, inductively-coupled plasma mass spectrometer (ICP-MS) instrument (Agilent Technologies Inc., Santa Clara, CA, USA) equipped with a $193 \mathrm{~nm}$ РнотоN Machines excimer Laser Ablation (LA) system (Рнотоn Machines Inc./Teledyne Cetac, Omaha, NE, USA) with 5 Hz repetition rate and an energy of around $0.06 \mu \mathrm{J}$ to $8 \mathrm{~J} / \mathrm{cm}^{2}$ (summary of data in Tables A2-A8). A very fast scanning data acquisition protocol was employed to minimise signal noise. Data acquisition for each analysis took three minutes (one minute on background, two minutes on signal). Ablation was carried out in He gas to improve sample transport efficiency and to provide stable signals and reproducible $\mathrm{Pb} / \mathrm{U}$ fractionation. Provided that constant ablation conditions are maintained, accurate correction for $\mathrm{U} / \mathrm{Pb}$ fractionation can then be achieved using an isotopically homogeneous zircon standard. Sample analyses performed in this study were run along with analyses of the Gemoc GJ-1 zircon standard [62]. This standard is slightly discordant, and has a TIMS ${ }^{207} \mathrm{~Pb} /{ }^{206} \mathrm{~Pb}$ age of $608.5 \mathrm{Ma}$ [63]. The other well-characterised zircon standard 91, 500 and Mud Tank were analysed within the measurement runs as an independent control on reproducibility and instrument stability. U-Pb ages were calculated from raw signal data using the software package GLITTER [64]. Individual time-resolved data analysis provides isotopically homogeneous segments of the signal to be selected for integration. We correct the integrated ratios for ablation related fractionation and instrumental mass bias by calibration of each selected time segment against the identical time segments for the standard zircon analyses.

Quantitative results for trace elements reported here were obtained through calibration of relative element sensitivities using the NIST-610 standard glass as external calibration standard. The BCR-2g 
basaltic glass standard and zircon GJ-1 reference material were analysed along the measurement runs as independent control on reproducibility and instrument stability. Theoretical Zr content was used for internal calibration for unknown zircon samples. The precision and accuracy of the NIST-610 analyses are $1-2 \%$ for REE, Y, Sr, Nb, Hf, Ta, Th and $\mathrm{U}$ at the ppm concentration level, and from $5 \%$ to $10 \%$ for $\mathrm{Ca}, \mathrm{P}$ and Ti (further details see in [65]).

Note, that the analysed concentration of trace dysprosium $(D y)$ that is considered relevant for its PL emission efficiency is low in the Sri Lankan samples (SL2: 6 to 41 ppm Dy; see Table A9) and comparably high in the Malawian samples (655 to 2123 ppm Dy; see Tables A7 and A8).

\section{Results and Discussion}

\subsection{Zircon's Amorphous Fraction Decoded from Dy photoluminescence}

The impact of self-irradiation-induced structural disorder on the PL emissions of REEs in zircon is exemplified in Figure 1. Excitation of zircon with a blue laser $\left(\lambda_{\text {exc }}=473 \mathrm{~nm}\right)$ typically results in emission of multiple trace REEs substituted in the crystal structure with that of $D y^{3+}$ and $\mathrm{Sm}^{3+}$ in the green-yellow spectral range being most intensive (Figure 1a; [48,50,51]). Figure 1 shows PL spectra from a Cambodian zircon sample from the Ratanakiri district that is characterised by very low degree of structural radiation-damage accumulation as detected with Raman spectroscopy ("Rata", see details in [66]). Further, spectra of mildly (sample M257, and M146) and severely radiation damaged zircon (sample G3, and N17) of the Ratnapura district, Sri Lanka are shown (see description of samples above, and [44]). Crystal-field split sub-level bands of the $D y^{3+}\left({ }^{4} \mathrm{~F}_{9 / 2} \rightarrow{ }^{6} \mathrm{H}_{13 / 2}\right)$ emission may be easily identified. These narrow bands increasingly broaden and decrease in intensity with progressive accumulation of radiation damage (Figure 1a; cf., [44]). The $D y^{3+}$ emission of a completely amorphised zircon sample (N17) is degenerated to a broad hump with a lack of the typical fine-splitting. Indeed, this degenerated broad-band emission of $D y^{3+}$ is typical for materials with absent long-range order such as reported for glasses $[67,68]$. A detailed investigation of spectra of partly radiation damaged samples reveal that fine-split bands not only broaden appreciably with an increasing degree of structural damage, but also superimpose a broad-band contribution that resembles the shape of the Dy emission of the completely amorphised zircon N17 (see red-hatched curve in Figure 1b).

We consequently interpret this contribution in $D y^{3+}$ spectra of partly radiation-damaged samples M146 and G3 as emissions arising from Dy ions in a structurally disordered "amorphised" cationic environment. This aspect is illustrated in more detail by Figure 2. A schematic energy level diagram of the $4 f^{9}$ electronic configuration of $D y^{3+}$ is shown in Figure 2a. The most intensive PL transition ${ }^{4} \mathrm{~F}_{9 / 2} \rightarrow{ }^{6} \mathrm{H}_{13 / 2}$ that is of interest here is indicated. Note, that each electronic level is split into fine sub-levels in dependence of the local anionic crystallographic coordination. Each Dy ion, hence, acts as an individual structural probe, in which subtle changes of the local crystal-field may have a strong effect on its luminescence emission. Figure $2 b$ shows a graphical representation of a molecular-dynamics simulation of a single $30 \mathrm{keV}$ recoil in zircon which typically decays from a single $\alpha$-decay event (modified after Trachenko et al. [69]). For illustration, we graphically add random substitutions of $D y$ ions on Zr-sites that are used as luminescence probe in this study (blue balls in Figure 2b). Note, that the zircon structure is heavily altered on the local atomic scale upon a recoiling daughter nucleus and cause the $D y$-probes to be located finally in various, structurally different sites. These may be fully ordered crystallographic environments which have not been affected by the impact of $\alpha$-decay events. Other sites in close proximity to the impact area may be (strongly) stressed but still intact, whereas the structure is completely altered along recoil trajectories, i.e., with breakdown of atomic bonds and loss of regular coordination around $D y$ ions. 


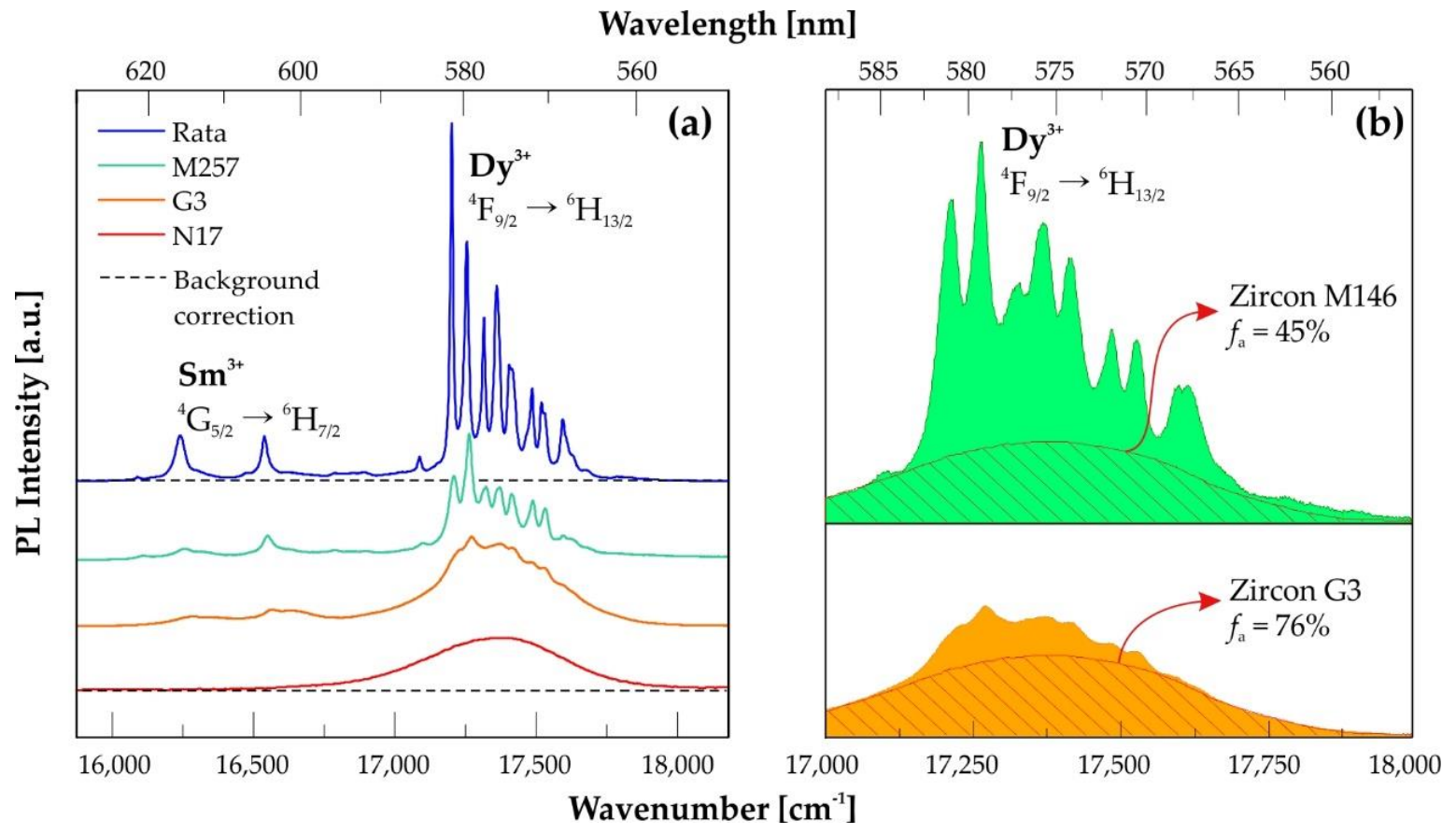

Figure 1. (a) Typical laser-induced photoluminescence spectra $\left(\lambda_{\text {exc }}=473 \mathrm{~nm}\right)$ of zircon from Ratanakiri, Cambodia (Rata) and Ratnapura, Sri Lanka (M257, G3, N17). Emissions of $\mathrm{Sm}^{3+}$ and $\mathrm{Dy}^{3+}$ were identified in the yellow spectral range between 550 and $620 \mathrm{~nm}$. Crystal-field split sub-level bands broaden and decrease in intensity with progressive accumulation of radiation damage from damage-free (Rata) to completely amorphised sample N17. (b) The $D y^{3+}$ emissions of partly radiation-damaged zircon samples M146 and G3 are characterised by broadened crystal-field split sub-level bands which superimpose a broad background component that resembles the shape of sample's N17 emission of $D y^{3+}$.
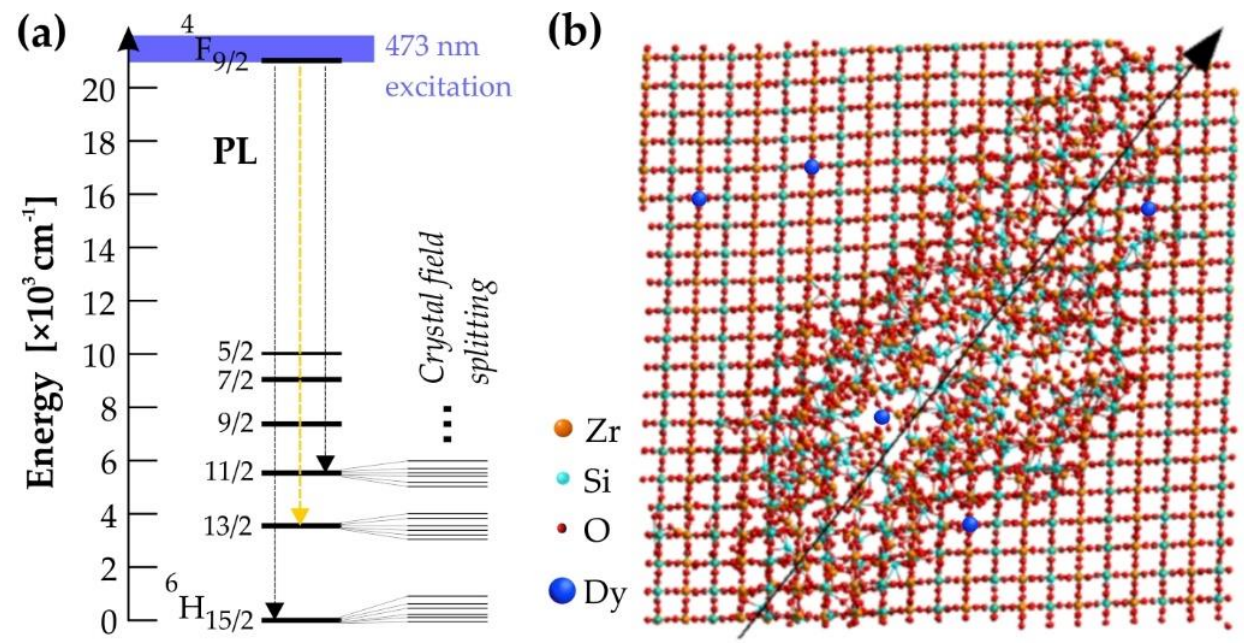

Figure 2. (a) A schematic energy-level diagram of $D y^{3+}\left(4 f^{9}\right.$ electron configuration) with its major luminescence transitions after excitation with a blue $473 \mathrm{~nm}$ laser (electronic level energies after Carnall et al. [70]). The free-ion levels are fine-split into so called "Stark levels" in dependence of the local crystal field. A stressed, altered, or completely destroyed structural environment has a great impact on crystal-field fine splitting, i.e., the luminescence emission. (b) Graphical representation of a molecular-dynamics simulation of a single $30 \mathrm{keV}$ recoil from a decay event in zircon (modified after Trachenko et al. [69]). The arrow indicates the moving direction of the decayed daughter nuclei. Blue balls represent random substitution of $\mathrm{REE}^{3+}$ ions (i.e., $D y^{3+}$ ) on $\mathrm{Zr}$-sites. Radiation damage alters the local structural environment of $D y^{3+}$ ions in affected areas. 
The detected PL of $D y^{3+}$ from the analysed volume of partly radiation-damaged zircon may, hence, be interpreted to represent a superposition of emissions from a multitude of individual $D y$ ions in sites with different degree of degradation. A high accumulation of radiation damage consequently result in PL emissions from high number of $D y$ ions in structurally altered sites. Given the assumption that $D y$ ions are distributed statistically within the analysed volume of our in-situ PL measurements and all of them contribute equally to the detected luminescence signal (i.e., the quantum conversion is the same and independent among different $D y$ sites), the relative integrated intensity of the deconvoluted amorphous component in relation to the overall integrated intensity, may give a reasonable estimate of the fraction of the amorphised material (amorphous fraction $f_{\mathrm{a}}$ ). In the examples of partly radiation-damaged samples M146 and G3 shown in Figure 1b, the red-hatched indicated component corresponds to ca. $45 \%$ and $73 \%$ of the signals surface integral, respectively.

The relation of the "amorphous" spectral component with respect to the overall signal integral is in principle independent of the absolute integrated intensity. For example, the presence of an increased number of statistically distributed $D y$ ions, due to the substitution of higher REE contents, may cause a higher emission intensity, but would not substantially alter the relation of $D y$ ions to be found in the radiation-damaged volume with respect to the total number of $D y$ ions present (i.e., if the assumption of a statistical distribution of $D y$ ions holds). Similarly, the estimation of the amorphous fraction by the latter approach may be accurate if other secondary PL quenching effects (e.g., effective absorption by broad-band irradiation-induced defect centres) may cause a substantial decrease of the overall luminescence intensity as typically reported for zircon e.g., in case of photoand cathodoluminescence [44] or ionoluminescence [71].

A major challenge for the quantitative estimation of the amorphous fraction according to the aforementioned approach is the accurate spectra deconvolution of the broad-band contribution of the $D y^{3+}$ emission that is considered to represent the "amorphous" component. Figure 3 presents two possible data-reduction strategies that may be applied (after background correction as indicated in Figure 1a). A first option is the fitting of a multitude of individual peaks that are modelled by Gauss-Lorentz (i.e., pseudo-Voigt) functions with their three spectral parameters (peak position, band width and amplitude) freely adjustable using an iterative least-squares optimization (Figure 3a). The amorphous component is treated here as a single Gaussian function with a fixed FWHM of $540 \mathrm{~cm}^{-1}$ and a peak position at $17,360 \mathrm{~cm}^{-1}(\sim 576 \mathrm{~nm})$ according to fitting results of the completely amorphised zircon sample N17 (cf., Figure 1a).

The amplitude of the broad band is then refined together with the free parameters of the other Gauss-Lorentz functions that fit to the narrow, crystal-field split sublevel bands. The major drawback using latter fitting procedure is the large number of variables to be optimised per single spectra. Here, 11 Gauss-Lorentz functions are used, that comprise 3 free parameters each, in addition to the broad-bands amplitude (34 free variables per spectrum in total, cf., Figure 3a). This is generally unproblematic for fitting single spectra, but may cause extensive computing time if large data-sets of hyperspectral maps with 50,000 to 80,000 and more data points (with a single spectrum per measurement point) need to be treated. Furthermore, this fitting procedure is incapable of accurately resolve low or absent fractions of the amorphous component. This is obvious from fitting results of sample "Rata" (Figure 3a), that is considered to represent a highly crystalline zircon sample with no radiation damage accumulated [66]. This fitting effectively introduced a significant amorphous component as background to optimise the determination coefficient $\left(R^{2}\right)$ although this sample is considered free of any measurable structural radiation damage.

To eliminate latter problems, we tested an alternative least-squares fitting procedure that is based on multiple reference spectra (so-called "loadings") with their individual amplitude (scaling) as free parameter optimised against experimental data (classic least-squares fitting, CLS). Loadings comprise spectra that are considered to represent (i) non-radiation damaged, crystalline samples (e.g., sample Rata or other annealed zircon samples); (ii) a reference that represent the amorphous component (e.g., the completely amorphised sample N17, cf., Figure 1a); and (iii) multiple references that represents slightly affected, stressed, but still crystalline volumes (cf., Figure 2b). 


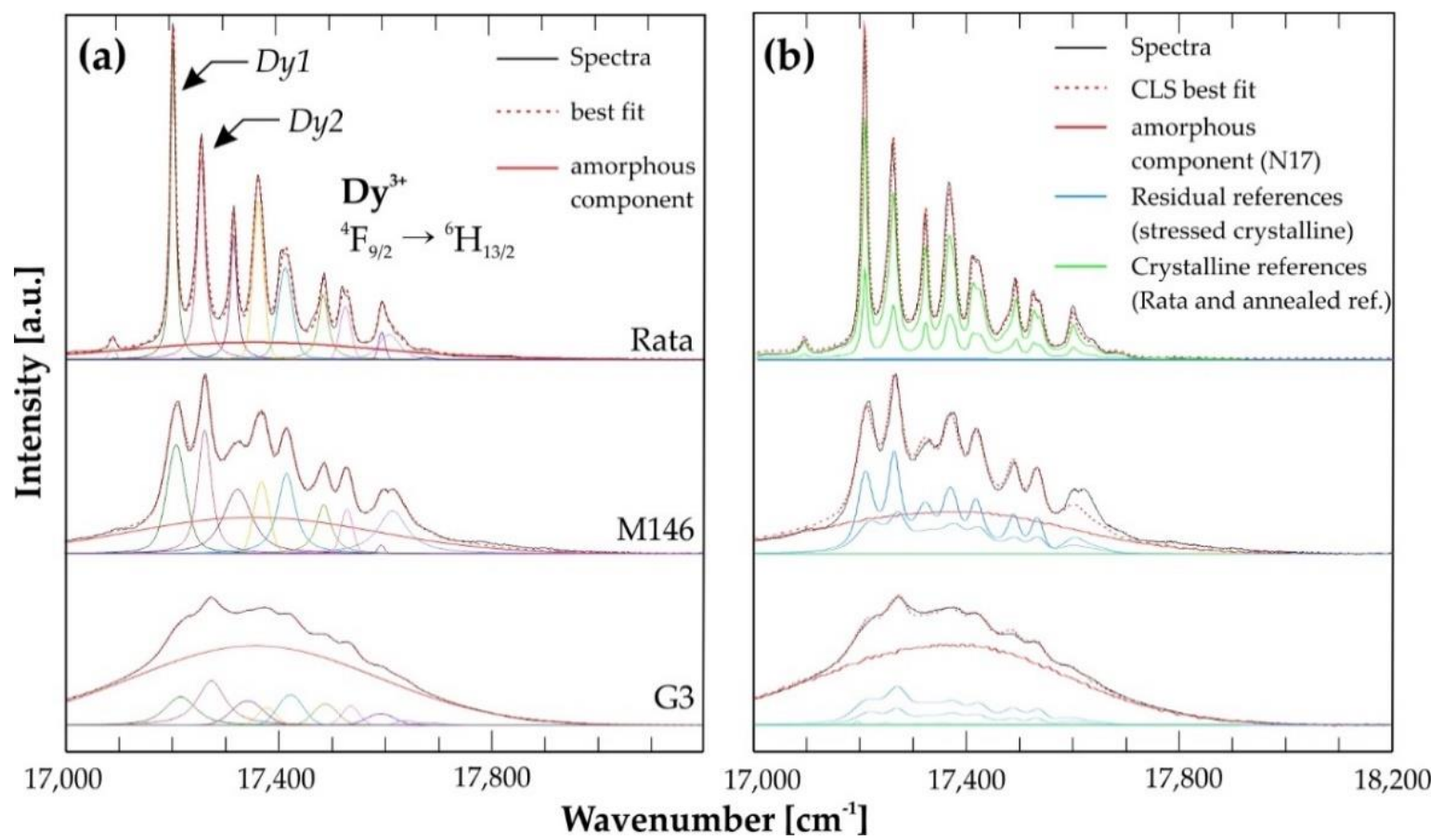

Figure 3. Graphical fitting results that estimate the amorphous fraction $f_{\mathrm{a}}$ from the laser-induced PL emission of $D y^{3+}\left({ }^{4} \mathrm{~F}_{9 / 2} \rightarrow{ }^{6} \mathrm{H}_{13 / 2}\right)$ using two different least-square deconvolution procedures on the example of zircon samples Rata, M146 and G3. (a) Individual crystal-field split sub-level bands are modulated with individual Gauss-Lorentz functions with spectral position, FWHM and amplitude treated as free variables that are optimised to fit best with experimental data. The amorphous component is modelled and best described using a Gaussian function with a variable amplitude, but with fixed FWHM of $540 \mathrm{~cm}^{-1}$ and peak position at $17,360 \mathrm{~cm}^{-1}(\sim 576 \mathrm{~nm})$. (b) Classic least-square (CLS) fitting procedure that takes advantage of multiple references, so-called "loadings". Those comprise spectra that are considered to represent non-radiation damaged, crystalline samples (e.g., sample Rata or other annealed zircon samples) and a reference from a completely amorphised sample (N17, cf., Figure 1a). Note that band-broadening is accounted for by using several residue spectra of partly-radiation damaged samples with the amorphous component subtracted according to the fitting presented in (a).

The latter non-amorphous, but affected sample volume causes narrow crystal-field split bands to effectively broaden with an increasing accumulation of radiation damage. This band broadening is accounted for in this fitting procedure by using residue spectra of partly-radiation damaged samples with broadened sub-level bands, but with the amorphous component subtracted according to the first fitting procedure described above (cf., Figure 3a). Note, however, that relative band heights especially in crystalline samples may differ due to polarization- and orientation-dependent effects [52]. To minimize errors in the fitting of samples with unknown orientation, it is therefore advisable to use loadings that represents samples of variable crystal orientations. With respect to the first mentioned fitting procedure, the number of free variables to be optimised in this alternative procedure is considerably reduced (i.e., effectively the number of loadings: e.g., $1 \times$ amorphous component $+3 \times$ residual references + $3 \times$ crystalline references; cf., Figure $3 b$ ). This low number of free variables substantially minimize computing time of large data-sets, but may concomitantly results in a somewhat larger error because of less-accurate approximation of spectral components. Dependent on the number and type of loadings used, the amorphous fraction $f_{\mathrm{a}}$ estimated by this method readily vary $\pm 5 \%$. The major advantage, however, relies in the more accurate estimation of low and/or absent amorphous components by using suited "crystalline" reference loadings (cf., fitting results of sample Rata in Figure 3b). 


\subsection{Sri Lankan Zircon as Reference for the Verification of the PL-Based Estimation of the Amorphous Fraction}

Zircon samples from the Ratnapura district (Sri Lanka), are ideal candidates to test and verify the applicability of the proposed PL methodology. Due to the prolonged interest in this sample material in the past, the amorphous fraction $f_{\mathrm{a}}$ in Sri Lankan zircon may be easily inferred from the knowledge of the $\alpha$-dose as calculated from $U$ and Th concentrations and the age of the samples, respectively $[26,35,36]$. In addition to PL data on $f_{\mathrm{a}}$ from a series of well-studied homogeneous Sri Lankan samples (see Table A1), we included two large, but strongly heterogeneously zoned Sri Lankan samples to demonstrate the potential of this technique to operate in-situ with a spatial resolution on the micrometre length-scale. Figure 4 shows PL hyperspectral maps of these two zircon samples SL1 (Figure 4a) and SL2 (Figure 4b). Both samples were cut in halves with one half annealed during a heat treatment at $1300{ }^{\circ} \mathrm{C}$ for three days, and thereafter prepared as pairs in close proximity (see inset sketch in Figure 4 for details on preparation). This was done to compare counterparts of the same sample that are chemically analogous to the greatest possible extent, but different in the structural state with the heat-treated half, cleared of the accumulated radiation damage. The samples were scanned using an instrument-coupled, software-controlled, mechanical $x-y$ table with each pixel of the map being an individual laser-induced PL point-measurement. Each spectrum was then deconvoluted using an automated CLS fitting procedure according to the principle presented above and the result given colour-coded. As expected, the two halves of samples SL1 and SL2 differ strongly with respect to their structural state. No amorphous component was detected in spectra obtained from the heat-treated halves. In contrast, PL maps of the non-treated halves reveal internal growth zonation as well as secondary overgrowth features (see arrows as indicated in Figure 4b). Strong accumulation of radiation damage is found in zones with elevated concentrations of $U$ and Th (see e.g., concentrations of $U$ and Th indicated in Figure 4a). Element concentrations of $U$ and $\mathrm{Th}$, as well as isotope ratios for U-Pb age determination of various measurement spots on the zircon crystals SL1 and SL2 were obtained using LA-ICP-MS (see Table A2). Note, however, that we placed measurements in different zones of the heterogeneous samples, but just in those providing sufficient space for a laser-ablation spot (spot diameter $50 \mu \mathrm{m}$ ) and multiple PL measurements in close proximity.

Figure 5a shows a plot with the calculated $\alpha$-dose of each measurement spot together with data from homogeneous Sri Lankan references against their amorphous fraction $f_{\mathrm{a}}$ as obtained by PL (see detailed data and equation for calculation of the $\alpha$-dose in Table A1). Data points resemble very well the correlation of the amorphous fraction $f_{\mathrm{a}}$ vs. $\alpha$-dose (red curve in Figure 5a) given by Zhang and Salje [35]. Latter authors have summarised existent data on the amorphous fraction $f_{\mathrm{a}}$ of Sri Lankan zircon as obtained by three alternative bulk methods. Based on their data, a regression according to the direct impact model have been proposed as best-fit that describes the accumulation of the amorphous fraction $f_{\mathrm{a}}$ via:

$$
f_{a}=1-e^{-B_{a} \times D_{\alpha}}
$$

where $D_{\alpha}$ is the $\alpha$-dose and $B_{a}$ the amount of amorphous material produced per $\alpha$-recoil. A least-squares regression analysis of our data from Sri Lankan zircon using this model results in $B_{a}=2.87 \times 10^{-19} \mathrm{~g}$ $\left(\mathrm{R}^{2}=0.99\right)$, which is fairly close to a $B_{a}=2.73 \times 10^{-19} \mathrm{~g}$ given by Zhang and Salje [35]. Note, however, that Sri Lankan zircon samples may have experienced a considerable thermal event in the geological history, and, hence the radiation damage now present may be systematically lower than expected if no annealing would have affected their structural state. Based on Raman data, Nasdala et al. [32] have discussed a correction factor of $\times 0.55$ to the calculated $\alpha$-dose, to account for geothermal annealing of Sri Lankan zircon ("effective" $\alpha$-dose, see [32]). Within the context of the direct impact model (Equation (1)) this correction concomitantly results in a "true" $\mathrm{B}_{\mathrm{a}}$ of $\sim 4.96 \times 10^{-19} \mathrm{~g}$ of amorphised material per $\alpha$-recoil (i.e., $\sim 2.73 \times 10^{-19} \mathrm{~g}$ divided by 0.55 ; see discussion below along with Figure $9 \mathrm{~b}$ ). 


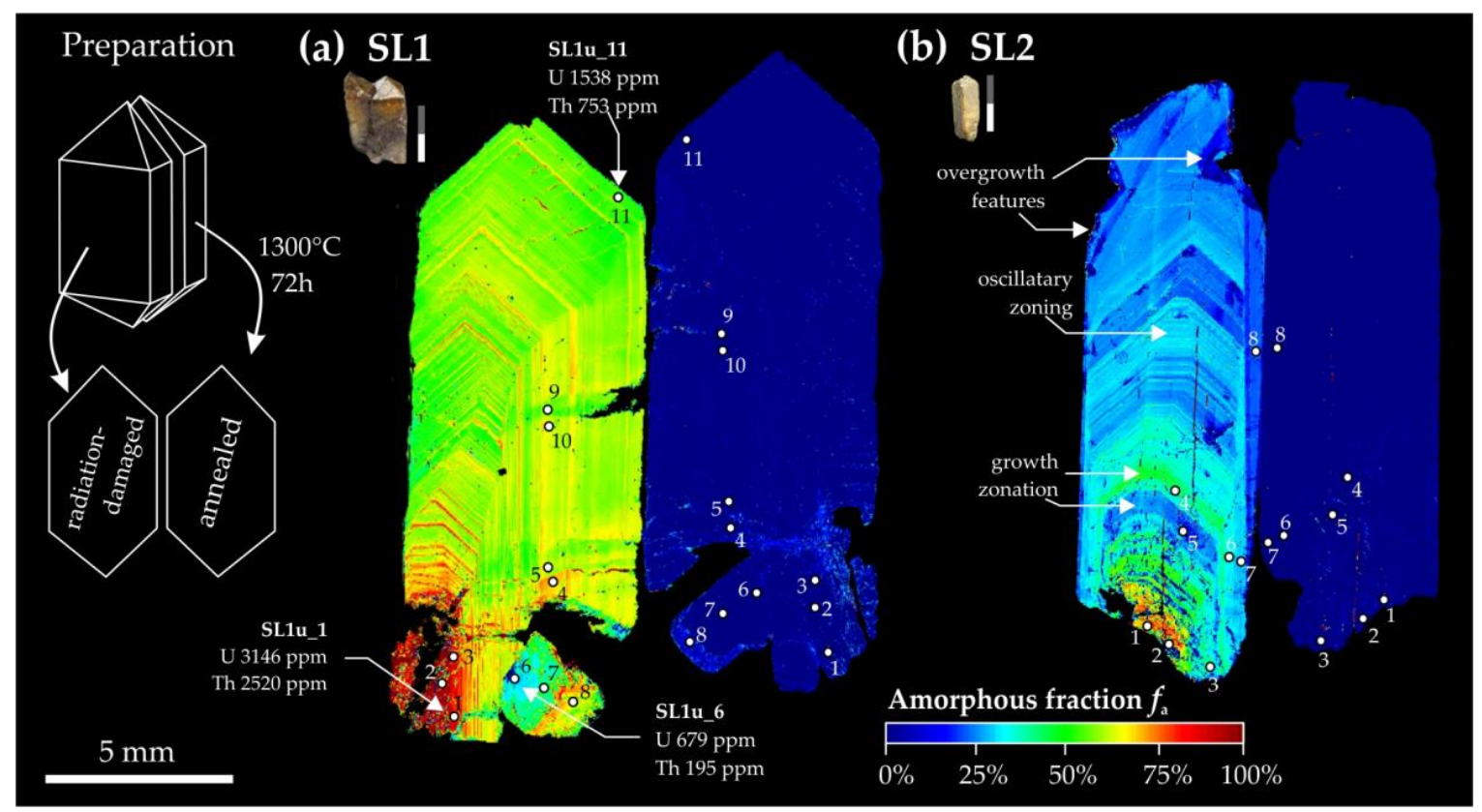

Figure 4. Photoluminescence hyperspectral maps of two large, heterogeneous Sri Lankan zircon single-crystals, SL1 (a) and SL2 (b). The crystals were cut in halves, with one half left in the original, radiation-damaged state and the other half annealed at $1300{ }^{\circ} \mathrm{C}$ for 3 days (see inset sketch). Mapping parameter is the amorphous fraction $f_{\mathrm{a}}$ as determined with the PL method (cf., Figure $3 \mathrm{~b}$ ) using a software-based least-squares fitting applied to a point-by-point scanned data-set. Radiation damage is detected in the original halves (left) with high $f_{\mathrm{a}}$ in zones with elevated $\mathrm{U}$ and Th concentrations (cf., Table A2 in Appendix A). The annealed halves (right) fully recovered crystallinity and show no amorphous component. Pairs of LA-ICP-MS analyses-spots on each half are indicated.

Due to the obvious strong variance of $f_{\mathrm{a}}$ among different growth zones in sample SL1 and SL2, we studied the impact of structural radiation damage on LA-ICP-MS isotopic age determination in more detail. We compared concordant ${ }^{206} \mathrm{~Pb} /{ }^{238} \mathrm{U}$ ages obtained from laser-ablation measurement spots in chemically equivalent growth zones on both, the untreated radiation-damaged and the annealed crystal half with the crystallinity recovered (see indicated pairs of measurement spots in Figure 4). ${ }^{206} \mathrm{~Pb} /{ }^{238} \mathrm{U}$ ages obtained from the untreated, radiation-damaged half of sample SL2 were found to be systematically older with increasing $\mathrm{Th}+\mathrm{U}$ concentration and, hence, increasing $f_{\mathrm{a}}$ present. Equivalent measurement spots on the annealed half of sample SL2 in contrast show no systematic correlation with the $\mathrm{Th}+\mathrm{U}$ content, but a substantially lower mean ${ }^{206} \mathrm{~Pb} /{ }^{238} \mathrm{U}$ age. Whereas the radiation-damaged half of SL2 gives a mean ${ }^{206} \mathrm{~Pb} /{ }^{238} \mathrm{U}$ age of $531 \pm 12 \mathrm{Ma}(n=8$, MSWD $=17)$, the annealed half gives $514 \pm 3 \mathrm{Ma}(n=8, \mathrm{MSWD}=1.1)$ with a 4-times improved analytical precision (see Table A4). Bias of the isotopic ages as caused by secondary loss/gain of $\mathrm{U}$ or $\mathrm{Pb}$ isotopes is rather unlikely in this context and can be excluded here due to the fact that very similar regions of the very same crystals were probed and compared. Here, the detected bias of LA-ICP-MS ages may be interpreted to result from the impact of radiation damage itself. Indeed, various authors reported a radiation-damage matrix-effect that is discussed to be caused by the altered physico-mechanical properties and, hence, laser-ablation behaviour of zircon in dependence of its damage accumulation [72-74]. Thus, an appropriate heat treatment of zircon samples prior to $\mathrm{U}-\mathrm{Pb}$ isotope dating by LA-ICP-MS has been suggested to substantially improve its precision and accuracy (see discussion in [75,76]). Significant changes in physical and chemical properties of radiation-damaged zircon have been reported to typically result in more effective ablation rates that is evident in deeper ablation pits, and generally cause isotope ages to appear systematically older [73,74]. 
(a)

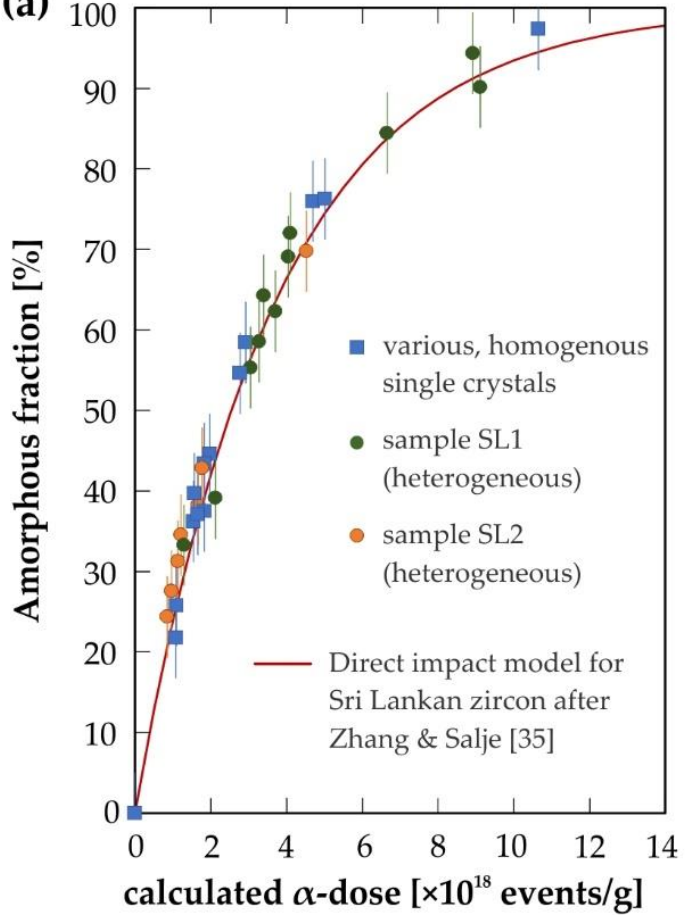

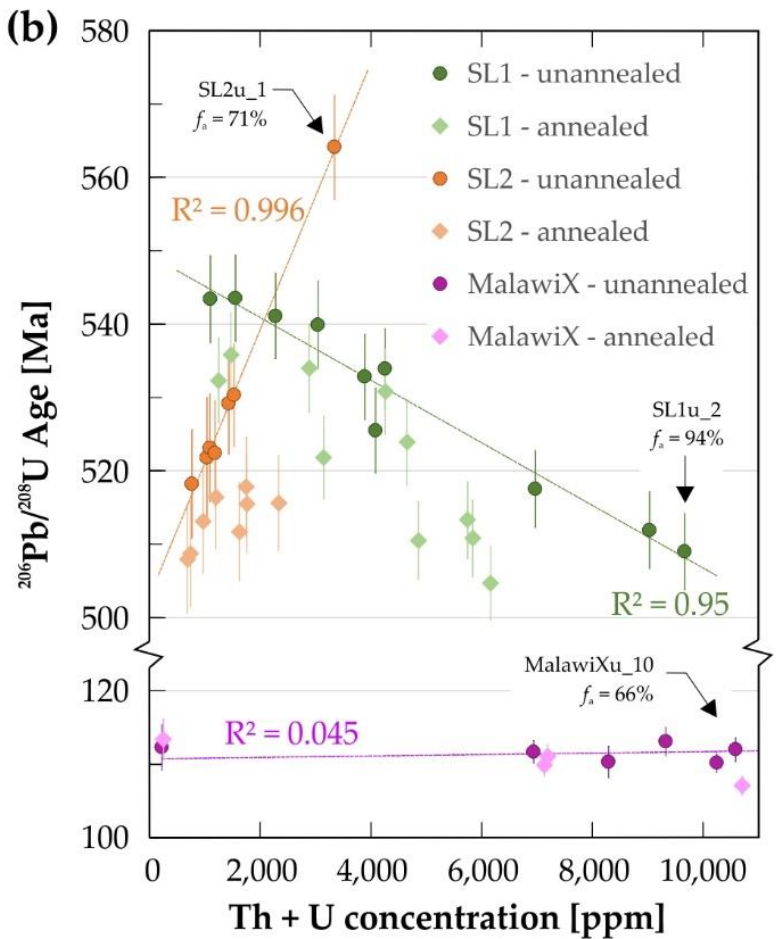

Figure 5. (a) The calculated $\alpha$-dose of various Sri Lankan zircon samples (cf., Tables A1 and A2 in Appendix A) plotted against the amorphous fraction $f_{\mathrm{a}}$ determined using the PL method (cf., Figure $3 \mathrm{~b}$ ). Within analytical uncertainty $(2 \sigma)$, data points lie on the regression curve (red) given by Zhang and Salje [35], who applied the direct-impact model to data of Sri Lankan zircon obtained from various alternative, bulk methods. (b) Obtained concordant $\mathrm{U}-\mathrm{Pb}$ ages plotted against $\mathrm{U}+\mathrm{Th}$ concentrations from multiple measurement spots on the annealed and unannealed halves of zircon samples SL1, SL2 and MalawiX. Linear regressions of data points from radiation-damaged, unannealed halves are indicated. Note, that bias of ${ }^{206} \mathrm{~Pb} /{ }^{238} \mathrm{U}$ ages is present irrespective of the radiation damage accumulated ( $f_{\text {a }}$ indicated for selected measurement spots).

In contrast to the latter, we observed the exact opposite behavior for Sri Lankan sample SL1. The ${ }^{206} \mathrm{~Pb} /{ }^{238} \mathrm{U}$ ages obtained from various measurement spots on unannealed zircon SL1 systematically appear younger, although an even higher amorphous fraction up to complete amorphisation was detected (cf., spots 1-3 on sample SL1 with $f_{\text {a }}$ up to $94 \%$; indicated in Figure 5 b, data see Table A2). Note that the trend from older to younger ages with increasing $U+$ Th concentrations does not follow the expected age progression as evident from the growth zonation. Here, the core of zircon SL1 with the highest $f_{\mathrm{a}}$ and $\mathrm{U}+$ Th concentrations yield the youngest LA-ICP-MS isotopic age (cf., spot SL1u_2 in Figure $5 \mathrm{~b}$ ). The annealing procedure applied to sample SL1 had a minor effect on the mean ${ }^{206} \mathrm{~Pb} /{ }^{238} \mathrm{U}$ ages only and its precision was not improved substantially. The radiation-damaged half of SL1 gives a mean ${ }^{206} \mathrm{~Pb} /{ }^{238} \mathrm{U}$ age of $528 \pm 9 \mathrm{Ma}(n=11, \mathrm{MSWD}=22$; $\mathrm{cf}$., Table A3), whereas the annealed half gives $520 \pm 7 \mathrm{Ma}(n=11, \mathrm{MSWD}=16 ;$ cf., Table A3).

Moreover, a third zircon example (sample MalawiX) from a completely different geological setting and with a much younger geological age shows no systematic age bias at all; neither in correlation with the $U+T h$ concentration, nor with the amount of radiation damage present (see samples characteristics in Figure 7a below). Note, that this sample contains huge amounts of REEs, $U$ and Th with growth zones that reaches an $f_{\mathrm{a}}$ value up to $72 \%$ (cf., spot MalawiXu_13 in Table A2). These strongly radiation-damaged zones in Malawi zircon yield very consistent ages in comparison to zones that accumulated almost no damage (cf., Table A5). Accordingly, the difference of mean ${ }^{206} \mathrm{~Pb} /{ }^{238} \mathrm{U}$ ages between unannealed (112 $\pm 1.3 \mathrm{Ma} ; n=9$, MSWD = 3.4) and annealed half $(110 \pm 1.6 \mathrm{Ma}, n=9$, MSWD = 5.4) is small. The above contradicting results, however, indicate that the degree of structural 
radiation damage alone cannot fully explain the strong variance in isotope age bias of LA-ICP-MS measurements in general.

\subsection{PL Photoluminescence Compared to Raman Spectroscopy}

A detailed analysis of laser-induced PL spectra of $D y^{3+}$ in zircon revealed that crystal field fine-split sublevels obviously change in their spectral parameters with an increasing degree of structural radiation-damage accumulation (see bands labelled Dy1 and Dy2 in Figure 3a). Band widths appreciably broaden and peak positions shift to higher wavenumbers. Surprisingly, these changes correlate closely to changes in the Raman-band parameters of the $v_{3}\left(\mathrm{SiO}_{4}\right)$ symmetric stretching vibration as obtained from the Sri Lankan samples studied here (Figure 6). This supports similar results by Lenz et al. [44]. Note, however, that in this study, PL sublevel bands of $D y^{3+}$ were fitted with Gauss-Lorentz functions after subtraction of the amorphous component according to the principle discussed above (cf., Figure 3b). With respect to latter PL model (cf., Figure $2 b$ ), changes in $D y^{3+}$ sublevel band widths and positions strictly speaking refer only to non-affected crystalline and/or marginally affected domains that are stressed and distorted, but not being completely structurally disordered (i.e., 'amorphised'). Thus, the close correlation of band parameters of PL and Raman spectroscopic features may indicate that very similar information on the short-range order are obtained from two perspectives; i.e., structural distortion at the anionic $\mathrm{SiO}_{4}$-tetraheder as probed by Raman $v_{3}$ and that of cationic polyhedra substituted by $D y^{3+}$ probed by laser-induced PL.

Spectral band widths and their interpretation with respect to the degree of radiation damage, however, have been discussed to be biased by other factors that cause a random structural distortion and finally lead to inhomogeneous broadening. A major disturbing factor reported in this context is the substitution of especially heterovalent non-formula elements into the crystal structure. This has been documented e.g., for narrow PL bands of $\mathrm{Nd}^{3+}$ [52] and Raman bands [57] of monazite-(Ce). This chemically-induced band-broadening effect is generally considered less important in zircon due to the more restricted crystal-chemical flexibility. Studies by Geisler et al. [53] and Kempe et al. [56], however, revealed that the Raman band-widths of zircon indeed may systematically depend on elevated contents of $U$ and/or REEs. In this study, we included zircon sample material from the Mt. Malosa massif, Malawi that is known for its inhomogeneous broadening of Raman $v_{3}$ bands due to the very high amount of REE substitutions [56,59]. The two samples studied represent two different generations of zircon found in pegmatites around the Mt. Malosa, Malawi (see sample description above). Large, prismatic, brownish, intransparent crystals (sample MalawiX) have been interpreted to be of pegmatitic origin that grew in miarolitic cavities $[54,56,59]$, whereas yellowish, semi-transparent crystals (MalawiA) grew as a result of a hydrothermal overprint during and/or shortly after the formation of the pegmatites itself ( 120 Ma, [56,59]). PL hyperspectral maps of cut-in-half samples reveal their complex growth and post-growth history (Figure 7a). Note, that the FWHMs of $D y$ emission bands are not used to estimate the radiation damage here, but analogously to PL maps presented in Figure 4, the amorphous fraction $f_{\mathrm{a}}$ was determined using the PL deconvolution procedure described above (cf., Figure 3b). 
(a)

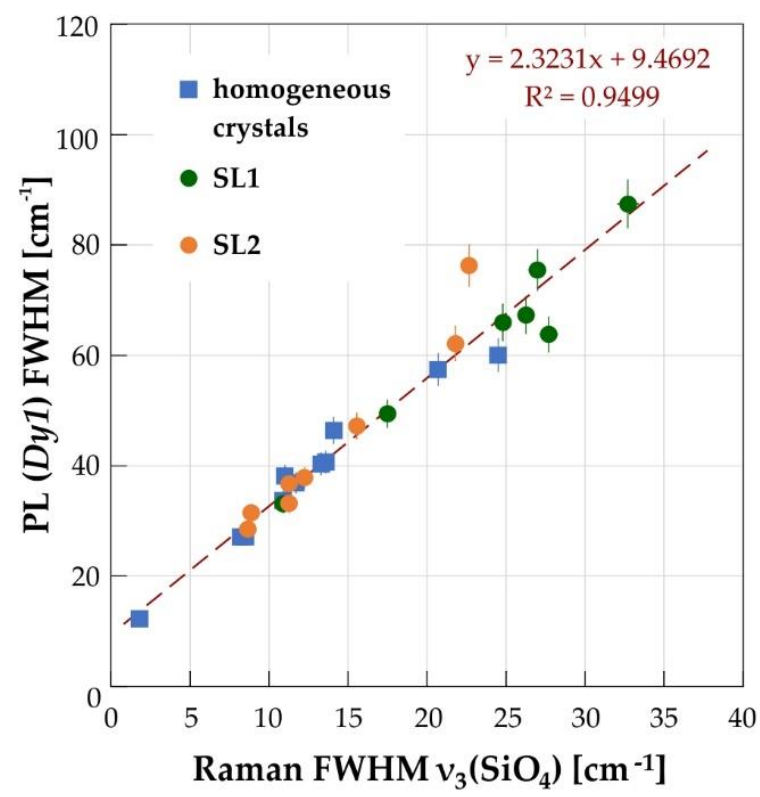

(b) Band positions

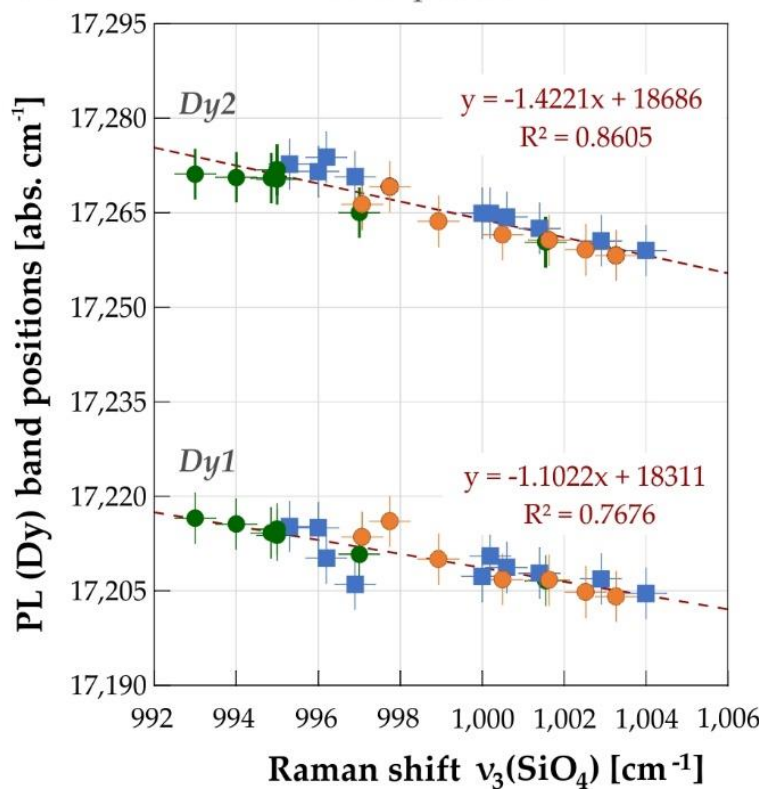

Figure 6. Comparison of spectral parameters of the Raman $v_{3}\left(\mathrm{SiO}_{4}\right)$ and laser-induced $D y^{3+}$ photoluminescence sublevel-bands of Sri Lankan zircon samples that are characterised by different degrees of radiation-damage accumulation. Measurement points from the unannealed halves of sample SL1 and SL2 are indicated in Figure 4. Photoluminescence sublevel-bands considered here are indicated as Dy1 and Dy2 in Figure 3a. Note, that $D y^{3+}$ sublevel-band parameters were fitted with Gauss-Lorentz functions after subtraction of the 'amorphous' broad-band component (cf., Figure 3). (a) The band-width of PL sublevel Dy1 closely correlates with that obtained from the Raman $v_{3}\left(\mathrm{SiO}_{4}\right)$ mode. Both, increasingly broaden with progressive accumulation of structural radiation damage. (b) Spectral band positions are inversely correlated. Whereas Raman band $v_{3}$ shifts to lower wavenumbers, PL bands Dy1 and Dy2 shift to higher peak positions with progressive damage accumulation.

Again, the annealed crystal halves do not show substantial structural damage left after heat treatment. In contrast, the untreated crystal-halves are characterised by multiple growth zones that accumulated considerable radiation damage in dependence of the amount of substituted $U$ and Th. Crystal growth of the large pegmatite-type zircon crystal MalawiX started from rounded inherited zircon and quartz inclusions (see arrows in Figure 7a). The zircon inclusion is characterised by low $\mathrm{U}$ and Th trace-element concentrations of 142 and 80 ppm, respectively, and hence, accumulated almost no significant radiation damage over geological periods of time (spot 11, Figure 7a, Table A2). Simultaneous crystallisation of zircon and quartz indicates Si-saturated growth conditions. Crystallization from a highly fractionated, late-stage growth environment is further indicated by geochemical provenance discrimination based on Hf and Y concentrations after Shnukov [77] as presented in Figure 8b. Concentrations of Hf and $\mathrm{Y}$ of the Malawian zircon samples fall well into the discrimination field characteristic of "felsic rocks with high $\mathrm{SiO}_{2}$ content" (group IV, see details in [65]). Inclusions of sample MalawiX were progressively enclosed by a zircon 'core' region with dominant pyramidal faces $\left(\begin{array}{lll}1 & 0 & 1\end{array}\right)$, followed by multiple growth zones that lead to a morphology with dominant prism faces $\left(\begin{array}{l}1 \\ 0\end{array} 0\right)$. Note, that zones in pyramidal growth direction are more enriched in $U$ and Th and hence, accumulated more structural radiation damage than zones in growth direction of the prism faces with less damage present (see "sector zoning" indicated by arrows in Figure 7a). Further, outer growth zones of sample MalawiX were heavily affected by secondary alteration (see arrows in Figure 7a again). These altered regions have a fine-grained micro-texture that according to Soman et al. [59] has been discussed to result from aqueous-solution driven dissolution-reprecipitation processes during hydrothermal alteration (cf., their Figure 1). In accordance to observations by latter authors, we detected elevated concentrations of 
$\mathrm{Ca}$ and Fe in this area which is considered a typical indicator for hydrothermally-driven alteration (cf., measurement points 4, 5, 11, and 12 of TE analyses presented in Table A7). In contrast, sample MalawiA show very subtle accumulation of radiation damage only, but especially in overgrowth zones that adds to slightly curvilinear prism faces of the crystal (note adapted scale colour-coding, Figure 7a). No obvious features of secondary alteration comparable to those found in sample MalawiX are detected in sample MalawiA.
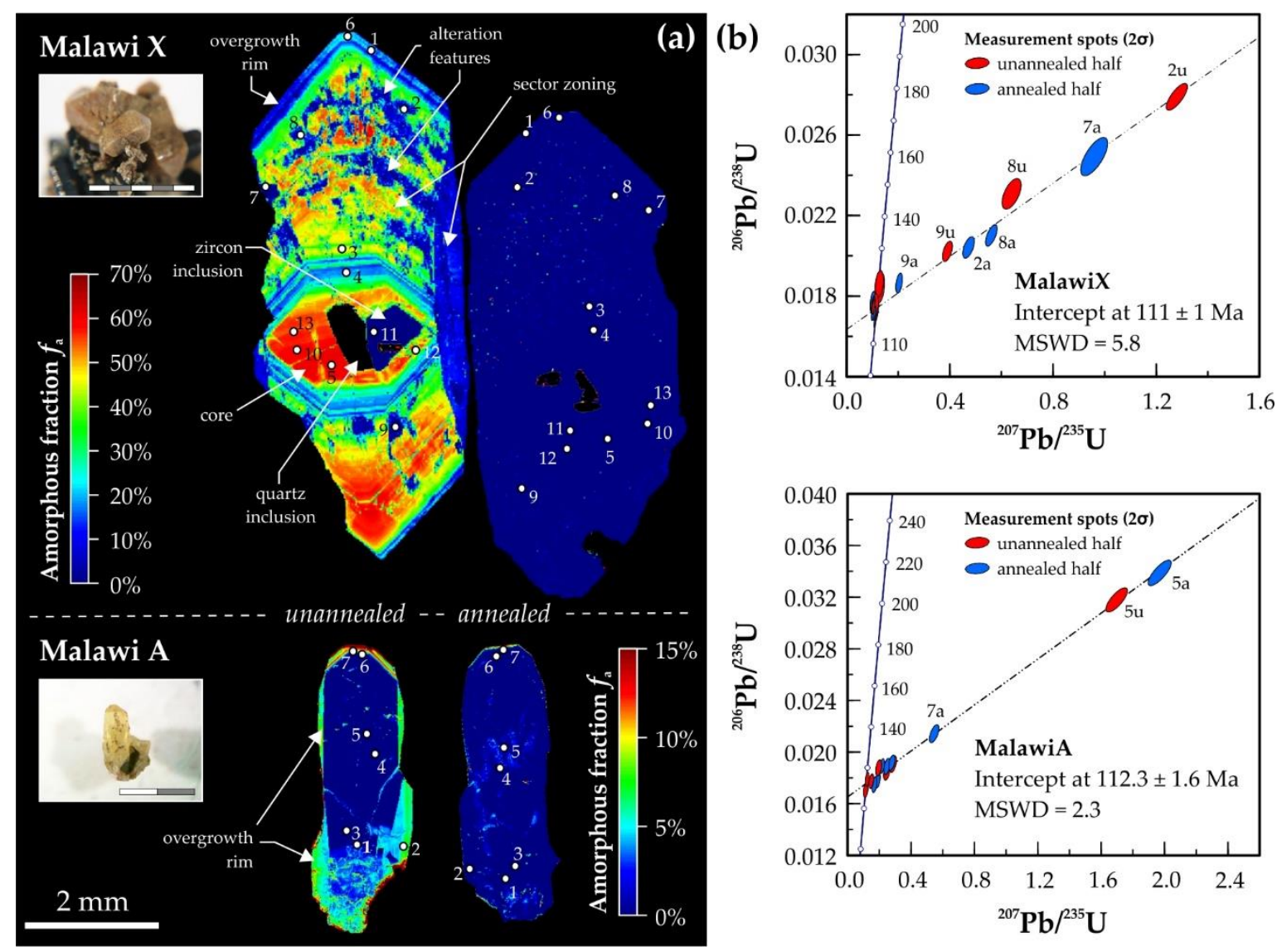

Figure 7. (a) PL hyperspectral maps of two zircon crystals from pegmatites of the Mt. Malosa massif, Malawi (see inset photographs) that were cut in half, with one half annealed at $1300{ }^{\circ} \mathrm{C}$ for three days (cf., Figure 4). The amorphous fraction $f_{\mathrm{a}}$ determined according to the deconvolution procedure of the $D y^{3+}$ photoluminescence as described above is given colour-coded. Note, that the scale may vary, e.g., to highlight subtle differences in radiation damage accumulation within sample MalawiA. Spots of LA-ICP-MS, detailed Raman and PL measurements are indicated. (b) U-Pb concordia and results of LA-ICP-MS isotope ratios obtained from measurement spots indicated in (a).

Zircon sample MalawiX gives a ${ }^{206} \mathrm{~Pb} /{ }^{238} \mathrm{U}$ age of $111 \pm 1 \mathrm{Ma}(n=18, \mathrm{MSWD}=5)$ as obtained from weighted mean of measurement spots with concordant isotopic ratios (cf., Table A5). Measurement spots located within heavily altered zones, however, exclusively yield discordant $\mathrm{U}-\mathrm{Pb}$ isotope ratios with a discordia line having a lower concordia intercept at a similar age of $111 \pm 1 \mathrm{Ma}$ (Figure $7 \mathrm{~b}$ ). This discordia age is indistinguishable to the concordant mean ${ }^{206} \mathrm{~Pb} /{ }^{238} \mathrm{U}$ age and confirms previous findings of a co-genetic and/or temporal closely related alteration during the formation of the pegmatite-type zircon [59]. Note that measurement spots within altered areas are likely to represent mixture analyses of various alteration phases, but no obvious spikes or disturbance of isotope ratios during time-resolved laser-ablation measurements were recorded. The latter, in principal, does not exclude the presence of very fine, homogeneously dispersed submicron inclusions within the ablated volume. The disturbance 
of $\mathrm{U}-\mathrm{Pb}$ isotope ratios that leads to the systematic discordia here, however, is interpreted to most likely result from entry of common $\mathrm{Pb}$ during the hydrothermal overprint.

Preferential alteration in sample MalawiX took place along growth zones that are characterised by strong damage accumulation as seen in relict zones with high $f_{\mathrm{a}}$ in the upper half of the crystal (Figure 7a). The upper half of the crystal was more likely exposed to circulating fluids as this part readily faced towards the open miarolitic cavity in comparison to the lower half close to the contact-wall (see left-side margin of the crystal). The lower half is obviously less altered but shares similar growth-zonation characteristics. Note, however, that no substantial radiation damage could have been accumulated at the time of alteration shortly after formation, and therefore, may not be considered as primary cause for the favored alteration here. We consider a preferential alteration due to the high amount of $U$, Th and REE substitution in this growth zones (that i.e., also lead to enhanced radiation damage over progressive geological time). The latter may be explained by an enhanced dissolution driving force as induced by the higher solubility of the trace element-rich zircon material in contrast to TE-poor zircon in hydrothermal solution (see discussion in [59]).

Interestingly, zircon sample MalawiA does not show characteristic alteration features, but LA-ICP-MS measurement spots placed across the crystal yielded relatively precise, but discordant $\mathrm{U}-\mathrm{Pb}$ isotopic ratios (see Figure $7 \mathrm{~b}$ ). Only a few spots gave ratios that lie on the concordia within an error of $2 \sigma$ (cf., Table A6). The constructed discordia gives a lower intercept age of $112.3 \pm 1.6 \mathrm{Ma}$, that is, again, close to the age of formation and alteration of the pegmatitic zircon MalawiX. The consistent discordia trends of both zircon-types, altered MalawiX as well as MalawiA, underpins their close hydrothermal genetic relation with a very similar isotope disturbance as caused by incorporation of common $\mathrm{Pb}$. Common $\mathrm{Pb}$ in yellowish "hydrothermal" type of zircon from Mt. Malosa have been confirmed also by $\mathrm{U}-\mathrm{Pb}$ sensitive high-resolution ion microprobe analyses reported by Kempe et al. [56]. The hydrothermal nature of zircon sample MalawiA is, in addition, supported by geochemical indications that are illustrated in Figure 8. According to Hoskin [78], zircon which crystallize at hydrothermal conditions typically has elevated concentrations of especially LREEs and therefore gives substantially flattened chondrite-normalised REE concentration patterns in comparison to their magmatic analogue. This is clearly evident from REE patterns shown here (Figure 8a). Moreover, the less pronounced $\mathrm{Ce} / \mathrm{Ce}^{*}$ anomaly of sample MalawiA in comparison to that of sample MalawiX supports its hydrothermal nature [78]. Note, however, that overall REE concentrations and their patterns are approximately one order of magnitude higher than those reported by Hoskin [78] for their hydrothermal zircon samples. Here, total REE concentrations reach very high values of around $3 \mathrm{wt}$. $\%$, whereby the REE totals surprisingly do not differ substantially between both Malawian sample types (cf., Tables A7 and A8).

Their major difference is the strong enrichment of LREEs on the expense of HREE and the obvious lack of $\mathrm{P}$ for charge compensation in sample MalawiA (cf., $<100$ ppm P in Table A8). In accordance to results reported by Kempe et al. [56], this unusual crystal chemistry has a substantial impact on the Raman spectroscopic band widths. In Figure 9a, the correlation of Raman $\left(v_{3}\right)$ FWHMs in dependence on the accumulated $\alpha$-dose of reference samples are shown. Those references are conclusively discussed not to be affected by geothermal annealing in the geological past and, hence, have retained all of their structural damage [22]. Whereas Raman band-widths obtained from MalawiX scatter around latter calibration line, obtained FWHMs from measurement spots on MalawiA are systematically broader than expected from their calculated, relatively low $\alpha$-dose (see blue circles in Figure 8a). Obtained FWHMs of 12 to $15 \mathrm{~cm}^{-1}$ typically indicate a rather substantial accumulation of radiation damage $\left(\sim 0.9-1.1 \times 10^{18}\right.$ events/g, [22]), but very low maximum doses of $0.16 \times 10^{18}$ events/g were calculated from $U$ and Th concentration data for sample MalawiA (Table A2). Raman band-widths of zircon that is (partially) annealed in the geothermal history typically plot at somewhat lowered FWHMs with respect to the calibration given by Nasdala [22]. Data points that plot above this line, hence, require cautious interpretation considering contradicting effects of band broadening. Kempe et al. [56] explained this band broadening by internal strain and distortion of the structure caused by the incorporation of 
large amounts of trivalent REEs that are widely charge-compensated by oxygen vacancies due to the insufficient quantity of other charge-balancing species such as pentavalent P on the Si-site or $\mathrm{U}, \mathrm{Nb}$ and $\mathrm{Ta}$, and others on the Zr-site (see discussion in [56]). An alternative charge-balancing mechanism that likewise may effectively compensate excess REEs in zircon involves the incorporation of $\mathrm{OH}^{-}$replacing $\mathrm{O}^{2-}$ in the anionic tetrahedral $\mathrm{SiO}_{4}$-unit [79]. Charge balance is maintained here via $\mathrm{H}^{+}+\mathrm{REE}^{3+}=\mathrm{Zr}^{4+}$. Kempe et al. [56] explicitly mentioned that no water or hydroxyl groups were found by Raman spectroscopic analyses. The vast amount of REE substitutions and their luminescence emissions, however, strongly interfere in spectral regions typical of $\mathrm{OH}$ and $\mathrm{H}_{2} \mathrm{O}$ vibrational modes (2000-3500 $\left.\mathrm{cm}^{-1}\right)$. Using multiple excitation wavelengths, we found strong PL artefacts in Raman spectra of the Malawian zircon samples within the respective spectral region (473 nm: $D y^{3+} ; 488 \mathrm{~nm}$ : $\mathrm{Ho}^{3+}$ and $\mathrm{Dy}^{3+}$; 532 and $514 \mathrm{~nm}: \mathrm{Sm}^{3+}$; and $633 \mathrm{~nm}: \mathrm{Nd}^{3+}$ ). If hydroxyl or water species are present in these zircon samples, their Raman signal simply is strongly obscured by latter $\mathrm{REE}^{3+}$ emissions. The potential of Raman spectroscopy to detect $\mathrm{OH} / \mathrm{H}_{2} \mathrm{O}$ species in zircon therefore needs to be questioned $[51,80]$. The exact nature of the substitution mechanisms that charge-balance the extraordinary amount of REEs in the Malawian zircon samples, hence, remain speculative.
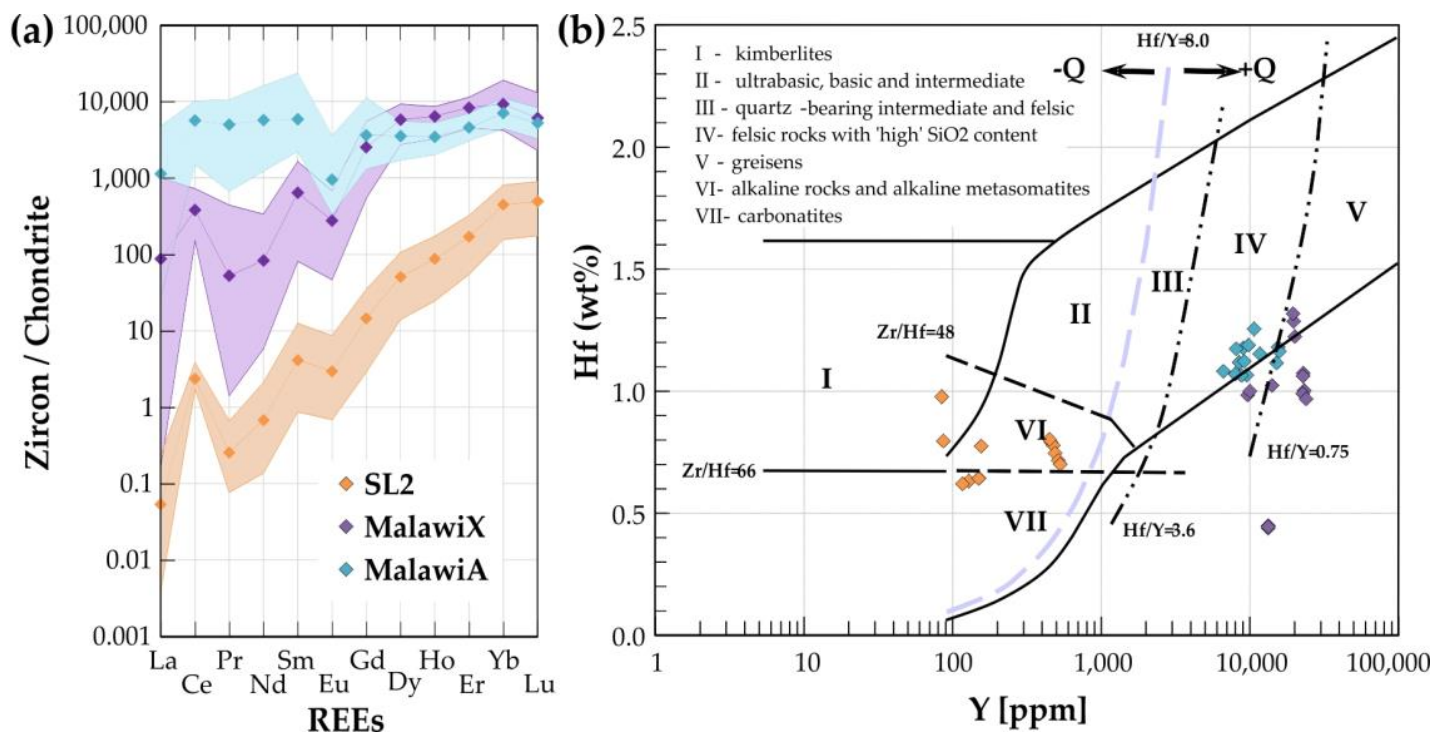

Figure 8. Results of LA-ICP-MS trace-element analyses of zircon samples from Sri Lanka (SL2) and Mt. Malosa pegmatites, Malawi obtained from their annealed crystal halves. Detailed results are given in Tables A7-A9. (a) Plots of mean chondrite-normalised REE concentrations of sample SL2 ( $n=13)$, MalawiX $(n=14)$, and MalawiA $(n=14)$ with their limits given colour-shaded, respectively. (b) Zircon provenance discrimination diagram after Shnukov [77] using Hf and Y concentrations. Expected fields of source rock type are indicated (details see [65]).

As illustrated in Figure 9b, results of the PL-based determination of $f_{\mathrm{a}}$ on the sample MalawiX are fairly in accordance to those of Raman band-width analysis (cf., Figure 9a). The $f_{\mathrm{a}}$ vs. $\alpha$-dose trend obtained for this sample resembles the typical accumulation behavior of zircon that is considered not to be affected by thermal annealing in the geological history. This calibration trend is given here as green curve in Figure $8 b$ and was inferred from the direct impact model of Zhang and Salje [35] for Sri Lankan zircon (cf., Figure 5a), but with $\alpha$-doses corrected for its geothermal annealing using a factor of $\times 0.55$ as proposed by Nasdala [22]. This correction results in $B_{a}=4.96 \times 10^{-19} \mathrm{~g}$ (see Equation (1) and discussion above). Note, that the latter correction of the direct-impact model by Zhang and Salje [35] yielded a marginally lower $B_{a}$ than reported by Palenik et al. $\left(B_{a}=5.48 \times 10^{-19} \mathrm{~g}\right.$; [8]). They have deduced $B_{a}$ indirectly from an approximation of Raman band-widths of Sri Lankan zircon to the Raman calibration line by Nasdala et al. [22] using an "effective" damage accumulation time period of $375 \mathrm{Ma}$ (see discussion in [8]). 
A regression analysis of Equation (1) to PL data obtained from Malawi samples, however, yields a $\mathrm{B}_{\mathrm{a}}=4.86 \times 10^{-19} \mathrm{~g}$ that is fairly close to the above mentioned back-calculated "true" $\mathrm{B}_{\mathrm{a}}$ of $4.96 \times 10^{-19}$ g. Values for $f_{\mathrm{a}}$ obtained from PL measurement points on sample MalawiA also fall onto latter trend. Based on these results, we may conclude that the pegmatitic-type zircon (sample MalawiX) and also, the hydrothermal-type zircon generation was likely not affected by further subsequent geothermal events after their formation $\sim 111 \mathrm{Ma}$ ago. The expected low accumulation of radiation damage is, in contrast to results from Raman FWHMs, not overestimated here (see again Figure 9). This is ascribed to a major advantage of the CLS-fitting procedure of $D y^{3+}$ emission spectra presented above (cf., Figure $3 b)$. A deconvolution that is based on input loadings allows to consider suited reference spectra from the annealed sample half of MalawiA, which restored complete crystallinity upon the applied heat treatment. Subtle changes in the spectral profile as caused by the amorphous component, hence, are detected most efficiently in direct comparison to this reference.
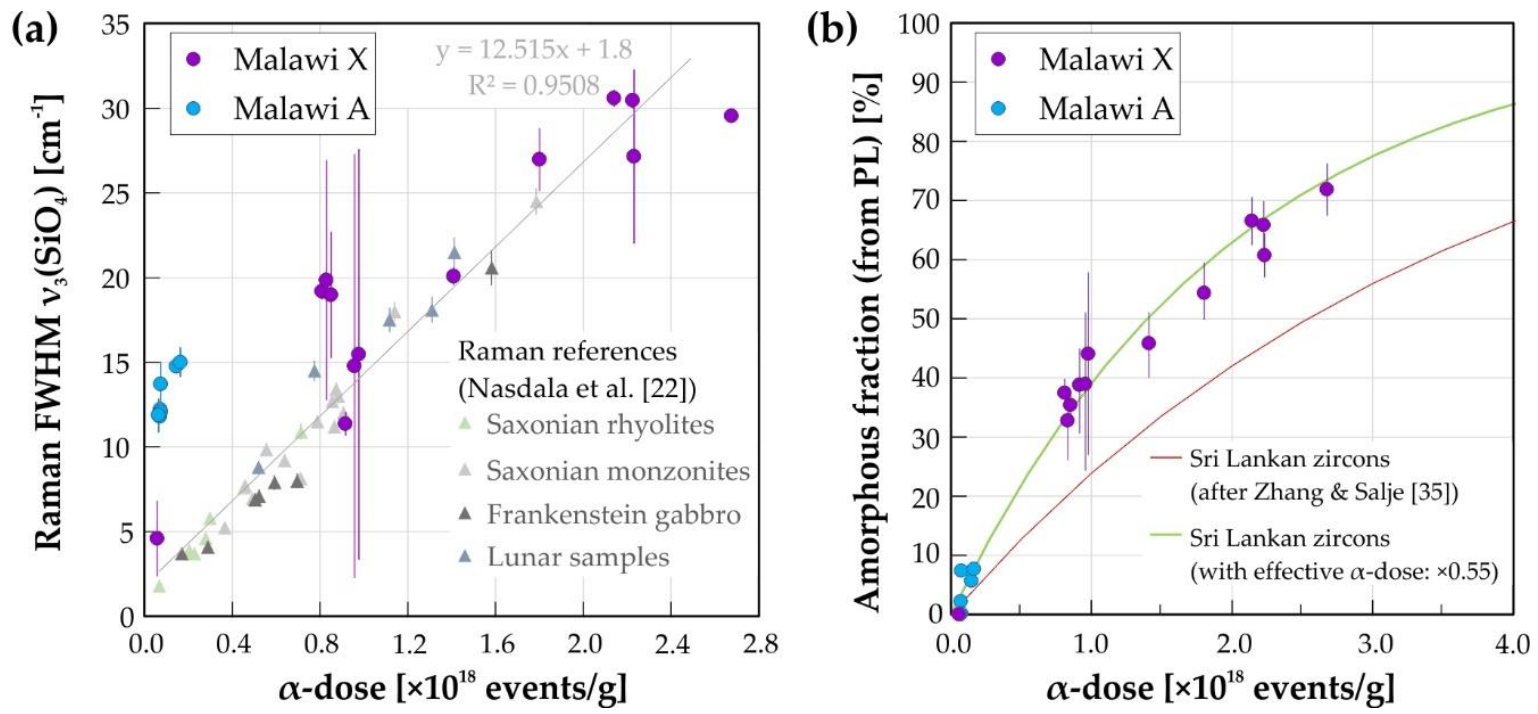

Figure 9. (a) Raman $v_{3}\left(\mathrm{SiO}_{4}\right)$ band widths of the Malawian samples $(\mathrm{X}, \mathrm{A})$ plotted against the $\alpha$-dose calculated from the age of the samples and the $U$ and Th concentrations (Table A2) obtained from multiple LA-ICP-MS measurement spots (indicated in Figure 7). (b) The amorphous fraction $f_{\mathrm{a}}$ as determined from the PL of $D y^{3+}$ from same measurement spots. The correlation $f_{\mathrm{a}}$ vs. $\alpha$-dose of Sri Lankan zircon according to the direct impact model after Zhang and Salje [35] is given as red curve (cf., Figure 5a). An additional (green) curve represents this correlation with Sri Lankan $\alpha$-doses corrected with a factor of $\times 0.55\left(\mathrm{~B}_{\mathrm{a}}=4.96 \times 10^{-19} \mathrm{~g}\right)$ that accounts for geothermal annealing and represents the 'effective' dose Sri Lankan zircon samples have experienced.

\section{Summary and Conclusions}

We documented a promising laser-based spectroscopic tool to non-destructively characterise radiation-damage in zircon in-situ on a micrometre length-scale. The proposed structural probe is based on the steady-state laser-induced photoluminescence of $D y^{3+}$ and opens up the opportunity to quantitatively visualize the amorphous fraction $f_{\text {a }}$ present in complexly zoned, heterogeneous samples using PL hyperspectral mapping. We found conclusive evidence that the $f_{\mathrm{a}}$ obtained from Sri Lankan zircon using a classic least-square (CLS) component fitting of $D y^{3+}$ emissions is consistent with reported literature values from alternative bulk techniques [33,35,36]. The latter implies further evidence for a direct impact model of radiation-damage accumulation (i.e., the accumulation of $f_{\mathrm{a}}$ ) in zircon with a progressive $\alpha$-dose. The proposed methodology, that comprise a deconvolution of the "amorphous" spectral component from $D y^{3+}$ luminescence emissions, has the advantage to provide a direct estimation of the amorphous fraction present without the need for calibration with related spectral changes, e.g., spectral band-width broadening of narrow crystal-field split $\mathrm{REE}^{3+}$ 
luminescence [44] or Raman bands [8], and hence may be used as a complementary in-situ spectroscopic technique. This is of specific surplus for occasionally observed samples that show chemically-induced band broadening of Raman and PL band-widths which biases individual calibrations of FWHM vs. damage accumulation, as exemplified in this study for hydrothermally-grown zircon from Mt. Malosa, Malawi.

Effective, laser-based excitation of $D y^{3+}$ luminescence in zircon is preferentially achieved using laser wavelengths in the UV to blue spectral region (e.g., with 488 or $473 \mathrm{~nm}$ as used in this study, [51]). Accurate spectral deconvolution of $D y^{3+}$ emission spectra requires a minimum spectral resolution of the applied spectrometer system to differentiate the broad-band component ascribed to result from $D y$ ions in structurally disordered regions from narrow crystal-field split bands that are interpreted to stem from slightly or non-distorted crystalline remnants. We recommend a minimum spectral resolution of better than 3 to $4 \mathrm{~cm}^{-1}$ ( $\sim .1 \mathrm{~nm}$ in the yellow spectral range) because narrow $D y^{3+}$ bands of the ${ }^{4} \mathrm{~F}_{9 / 2} \rightarrow{ }^{6} \mathrm{H}_{13 / 2}$ transition may have individual FWHMs down to $\sim 10 \mathrm{~cm}^{-1}(0.3 \mathrm{~nm})$ at room temperature (cf., Figure 6; [44]). Further, suited reference spectra from well-characterised sample material are needed to serve as loadings for a sound CLS fitting. Most importantly, those comprise spectra that (i) represents samples which underwent complete amorphisation, and (ii) samples that are considered to be fully crystalline samples and free of structural damage. The latter may be synthetic analogues or natural zircon samples that experienced very low $\alpha$-doses or have been annealed artificially using a suitable heat treatment (e.g., $72 \mathrm{~h}$ at $1300^{\circ} \mathrm{C}$ ).

Thermal annealing, either induced artificially by heat treatments and/or naturally as caused by geothermal events, may have an important impact on the structural state of zircon, and causes the detected amorphous fraction $f_{\mathrm{a}}$ to be substantially lower than expected from the calculated $\alpha$-dose based on $\mathrm{U}+$ Th concentrations and the age of the sample. Misfits in obtained $f_{\mathrm{a}}$ from a reference correlation, therefore, may provide important indications for potential geothermal events in the sample's geological history. In this study, we found that investigated Malawian zircon samples did not experience a substantial impact from geothermal events after their formation 111 Ma ago.

Careful comparison of LA-ICP-MS isotope ages of naturally, radiation damaged zircon with its chemically analogous, but annealed damage-free counterpart further reveal that the ablation behavior of altered zircon matrix may lead to a systematic bias of the isotope fractionation in dependence on the amount of accumulated radiation-damage. The mere quantity of damage alone, however, was found not to be an exclusive factor for obtained biases. Based on these results, we strongly suggest to initiate further studies that shed light on the role of structural radiation-damage affective to the analytical precision of LA-ICP-MS isotope dating; especially with focus on the impact of geothermal damage-annealing on the sub-microstructure of zircon.

We propose here that the concept of the presented PL methodology may be extended easily (a) to other accessory minerals and ceramic waste-form materials of interest, and (b) to other REE ${ }^{3+}$ species to be used as potential structural probes, especially those that are excitable/emissive in complementary spectral ranges (cf. for instance, $\mathrm{Nd}^{3+}$ in orthophosphates [58]). The estimation of $f_{\mathrm{a}}$ in zircon and other mineral phases using laser-induced PL spectroscopy has numerous analytical advantages. One of the major benefits is the possibility to perform spot analyses non-destructively using highly confocal spectrometers coupled to optical probe-heads or microscopes with the latter operating on the $\mu \mathrm{m}$ length-scale. Further, this technique has great potential to be applied as a remote technique with minimal sample preparation needed, e.g., for minute in-situ monitoring of self-irradiation experiments with ${ }^{238} \mathrm{Pu}$-, ${ }^{241} \mathrm{Am}$, or ${ }^{244} \mathrm{Cm}$-doped analogue ceramics through transparent containers.

Author Contributions: All authors listed have made a substantial, direct, and intellectual contribution to the presented study. Conceptualization \& project administration, C.L., G.R.L.; methodology, C.L.; E.B.; draft preparation, C.L.; review and editing, G.R.L., E.B. All authors have read and agreed to the published version of the manuscript.

Funding: C.L. and E.B. gratefully acknowledge the use of instrumentation funded through an honorary-associate agreement with the ARc CCFs/Gemoc at Macquarie University, Sydney. The analytical data were obtained using instrumentation funded by DEST Systemic Infrastructure Grants, ARC LIEF, NCRIS/AuScope, industry partners 
and Macquarie University. This is contribution 1418 from the ARC Centre of Excellence for Core to Crust Fluid Systems (http://www.ccfs.mq.edu.au) and 1361 in the GEMOC Key Centre (http://www.gemoc.mq.edu.au). Financial support of C.L. and funding for publishing open access was provided by the Austrian Science Fund (FWF), through project J3662-N19 granted to C.L.

Acknowledgments: Thanks are due to Lu, K., and Palmer, T. (ANSTO) and Wagner, A. (University Vienna) for sample preparation. We thank Nasdala, L. (University Vienna) providing Sri Lankan zircon reference material, with sample M146 provided by Hofmeister, W. (Institute of Gemstone Research, Idar Oberstein and Mainz), and zircon G3 by Kennedy, A.K. (Curtin University, Perth). Sample MalawiA was made available by Kolitsch, U. (NHM Vienna; Sample reference-No.: N3848). We are indebted to Karatchevtseva, I. (ANSTO), Chanmuang Nasdala, C. and Talla, D. (University Vienna) for technical assistance and furnace heat-treatments of samples. We also gratefully acknowledge technical assistance with LA-ICP-MS instrumentation by Murphy, R. and Lai, Y.-J. (Macquarie University, Sydney).

Conflicts of Interest: The authors declare no conflict of interest.

\section{Appendix A}

Table A1. Uranium and thorium concentrations, ages, calculated $\alpha$-doses, and the amorphous fraction $f_{\mathrm{a}}$ of various homogeneous, Sri Lankan zircon crystals and a damage-free reference from the Ratanakiri district, Cambodia (Rata).

\begin{tabular}{|c|c|c|c|c|c|}
\hline Sample & $\begin{array}{c}\mathrm{U}^{*} \\
{[\mathrm{ppm}]}\end{array}$ & $\begin{array}{c}\text { Th * } \\
{[\mathrm{ppm}]}\end{array}$ & $\begin{array}{c}{ }^{206} \mathrm{~Pb} /{ }^{238} \mathrm{U} \text { Age * } \\
\text { [Ma] }\end{array}$ & $\begin{array}{c}\text { Calc. } \alpha \text {-dose } \dagger \\
{\left[\times 10^{18} \text { events } / g\right]}\end{array}$ & $\begin{array}{c}\text { Amorphous } \\
\text { Fraction } \ddagger f_{\mathrm{a}}[\%]\end{array}$ \\
\hline CZ3 & $550 \pm 10$ & $30 \pm 2$ & $563.9 \pm 1.3$ & $1.05-1.10$ & 21.8 \\
\hline B188 & $556 \pm 24$ & $59 \pm 4$ & $559 \pm 8$ & $1.03-1.15$ & 25.8 \\
\hline BR1 & $796 \pm 13$ & $39 \pm 1$ & $558 \pm 13$ & $1.47-1.60$ & 36.2 \\
\hline BR231 & $772 \pm 10$ & $109 \pm 2$ & $571 \pm 4$ & $1.53-1.59$ & 39.7 \\
\hline M257 & $840 \pm 27$ & $235 \pm 20$ & $561.3 \pm 0.3$ & $1.66-1.78$ & 37.1 \\
\hline BR266 & $909 \pm 17$ & $201 \pm 7$ & $559.0 \pm 0.3$ & $1.77-1.88$ & 37.5 \\
\hline M146 & $923 \pm 17$ & $411 \pm 9$ & $567 \pm 4$ & $1.92-2.03$ & 44.6 \\
\hline M127 & $923 \pm 23$ & $439 \pm 11$ & $524.3 \pm 0.4$ & $1.78-1.88$ & 43.4 \\
\hline OR1 & $1490 \pm 70$ & $279 \pm 18$ & $522 \pm 3$ & $2.62-2.92$ & 54.6 \\
\hline G168 & $1499 \pm 33$ & $257 \pm 9$ & $547 \pm 3$ & $2.83-3.00$ & 58.4 \\
\hline G4 & $2355 \pm 84$ & $330 \pm 12$ & $564 \pm 5$ & $4.48-4.91$ & 76.0 \\
\hline G3 & $2572 \pm 96$ & $585 \pm 34$ & $542 \pm 5$ & $4.77-5.25$ & 76.3 \\
\hline N17 & $5568 \pm 114$ & $344 \pm 45$ & $551 \pm 7$ & $10.27-11.02$ & 97.4 \\
\hline Ràtá & $\overline{140} \overline{ \pm} \overline{1} 00$ & $90 \pm 80^{-}$ & $1 . \overline{2} \pm \overline{0} . \overline{3}$ & $\pm-\overline{0}$ & $\overline{0} . \overline{0}$ \\
\hline
\end{tabular}

Notes: Errors quoted are estimates that include errors of individual measurements and sample heterogeneity (scatter among multiple analyses).

* Sources for U and Th concentrations, ages, calculated $\alpha$-doses: Nasdala et al. [39] for M257, Nasdala et al. [40] for M127, Zeug et al. [66] for zircon from Ratanakiri, Cambodia (Rata). See Nasdala et al. [32] (and references therein) for all other samples.

$+\alpha$-doses were calculated from $\mathrm{U}-\mathrm{Pb}$ age and $\mathrm{U}$ and $\mathrm{Th}$ concentrations after:

$D=8 \cdot \frac{c_{u} \cdot N_{A} \cdot 0.9928}{M_{238} \cdot 10^{6}} \cdot\left(e^{\lambda_{238} \cdot t}-1\right)+7 \cdot \frac{c_{u} \cdot N_{A} \cdot 0.0072}{M_{235} \cdot 10^{6}} \cdot\left(e^{\lambda_{235} \cdot t}-1\right)+6 \cdot \frac{c_{T h} \cdot N_{A}}{M_{232} \cdot 10^{6}} \cdot\left(e^{\lambda_{232} \cdot t}-1\right)$,

where $c_{u}$ and $c_{T h}$ are the present actinide concentrations; $N_{A}$ is Avogadro's constant; $M_{238}, M_{235}$ and $M_{232}$ are the molecular weights of the parent isotopes; $\lambda_{238}, \lambda_{235}$ and $\lambda_{232}$ are the respective decay constants and $t$ is the age $[6,22,25]$.

$\ddagger$ The amorphous fraction as obtained with the PL method (cf., Figure 1b). Minimum errors of $\pm 5 \%$ need to be considered for scatter among multiple analyses and deviations due to different model loadings (cf., Figure 3b). 
Table A2. Uranium and thorium concentrations, calculated $\alpha$-doses, and the amorphous fraction $f_{\mathrm{a}}$ obtained from multiple measurement spots on the unannealed $(\mathrm{u})$, heterogeneous crystal halves of sample SL1 and SL2 from the Ratnapura district, Sri Lanka, and the samples MalawiA and MalawiX from the Mt. Malosa massif, Malawi.

\begin{tabular}{|c|c|c|c|c|}
\hline Samples & $\mathrm{U}[\mathrm{ppm}]$ & Th [ppm] & $\begin{array}{cc}\text { Calc. } & \alpha \text {-dose } \dagger \\
{\left[\times 10^{18}\right.} & \text { events } / g]\end{array}$ & $f_{\mathrm{a}} \ddagger[\%]$ \\
\hline \multicolumn{5}{|l|}{ Sample SL1 } \\
\hline SL1u_01 & 3146 & 2520 & 6.66 & 84.5 \\
\hline SL1u_02 & 4185 & 3519 & 8.93 & 94.4 \\
\hline SL1u_03 & 4269 & 3622 & 9.13 & 90.2 \\
\hline SL1u_06 & 679 & 195 & 4.06 & 33.3 \\
\hline SL1u_07 & 1161 & 107 & 3.45 & 39.1 \\
\hline SL1u_08 & 1807 & 118 & 1.30 & 58.6 \\
\hline SL1u_09 & 1806 & 1182 & 2.12 & 62.3 \\
\hline SL1u_10 & 1988 & 1211 & 3.28 & 69.1 \\
\hline SL1u_11 & 1538 & 753 & 3.72 & 56.1 \\
\hline \multicolumn{5}{|l|}{ Sample SL2 } \\
\hline SL2u_1 & 1271 & 710 & 4.53 & 69.8 \\
\hline SL2u_2 & 1010 & 341 & 3.54 & 60.7 \\
\hline SL2u_3 & 929 & 512 & 1.67 & 38.2 \\
\hline SL2u_4 & 940 & 430 & 1.77 & 42.8 \\
\hline SL2u_5 & 538 & 216 & 0.97 & 27.6 \\
\hline SL2u_6 & 660 & 339 & 1.14 & 31.2 \\
\hline SL2u_7 & 435 & 168 & 1.21 & 34.5 \\
\hline SL2u_8 & 444 & 134 & 0.85 & 24.4 \\
\hline \multicolumn{5}{|l|}{ MalawiX } \\
\hline MalawiXu_01 & 356 & 7934 & 0.81 & 37.5 \\
\hline MalawiXu_02 & 151 & 10,041 & 0.92 & 38.8 \\
\hline MalawiXu_03 & 364 & 19,465 & 1.80 & 54.3 \\
\hline MalawiXu_04 & 921 & 6018 & 0.85 & 35.4 \\
\hline MalawiXu_05 & 4543 & 5704 & 2.14 & 66.5 \\
\hline MalawiXu_06 & 586 & 13,959 & 1.41 & 45.8 \\
\hline MalawiXu_07 & 92 & 9289 & 0.83 & 32.7 \\
\hline MalawiXu_08 & 146 & 10,788 & 0.98 & 44.0 \\
\hline MalawiXu_09 & 244 & 10,138 & 0.96 & 38.9 \\
\hline MalawiXu_10 & 4744 & 5841 & 2.23 & 65.8 \\
\hline MalawiXu_11 & 142 & 80 & 0.06 & 0.0 \\
\hline MalawiXu_12 & 5153 & 4174 & 2.23 & 60.7 \\
\hline MalawiXu_13 & 5682 & 7105 & 2.68 & 71.8 \\
\hline \multicolumn{5}{|l|}{ MalawiA } \\
\hline MalawiAu_1 & 112 & 366 & 0.07 & 2.2 \\
\hline MalawiAu_2 & 130 & 320 & 0.08 & 7.4 \\
\hline MalawiAu_3 & 113 & 328 & 0.07 & 0.0 \\
\hline MalawiAu_4 & 119 & 369 & 0.08 & 0.1 \\
\hline MalawiAu_5 & 106 & 308 & 0.07 & 0.0 \\
\hline MalawiAu_6 & 157 & 1021 & 0.15 & 5.7 \\
\hline MalawiAu_7 & 146 & 1272 & 0.16 & 7.6 \\
\hline
\end{tabular}

Notes: $\uparrow \alpha$-doses were calculated from $\mathrm{U}$ and Th concentrations and the $\mathrm{U}-\mathrm{Pb}$ age using equation given in Table $\mathrm{A} 1$ (see also $[6,22,25]$ ). Mean weighted ${ }^{206} \mathrm{~Pb} /{ }^{238} \mathrm{U}$ ages as obtained from multiple LA-ICP-MS measurement spots on both, annealed and un-annealed halves were used for calculation (cf., Tables A3-A5).

$\ddagger$ The amorphous fraction as obtained with the PL method (cf., Figure $3 b)$. Errors of $\pm 5 \%$ need to be considered for scatter among multiple analyses and background correction. 
Table A3. U-Pb isotope ratios and ${ }^{206} \mathrm{~Pb} /{ }^{238} \mathrm{U}$ ages of the large, heterogeneous Sri Lankan zircon crystal SL1 with multiple analyses spots on both, the radiation damage-affected unannealed half $(\mathrm{u})$ and the heat-treated, annealed half (a) with its crystallinity recovered.

\begin{tabular}{|c|c|c|c|c|c|c|}
\hline \multirow{2}{*}{$\begin{array}{l}\text { Analysis } \\
\text { Spot }\end{array}$} & \multicolumn{4}{|c|}{ Isotope Ratios } & \multicolumn{2}{|c|}{ Ages [Ma] } \\
\hline & ${ }^{207} \mathrm{~Pb} /{ }^{235} \mathrm{U}$ & $\pm 2 \sigma$ & ${ }^{206} \mathrm{~Pb} /{ }^{238} \mathrm{U}$ & $\pm 2 \sigma$ & ${ }^{206} \mathrm{~Pb} /{ }^{238} \mathrm{U}$ & $\pm 2 \sigma$ \\
\hline SL1u_01 & 0.66538 & 0.0095 & 0.08358 & 0.0009 & 517.5 & 5 \\
\hline SL1u_02 & 0.66448 & 0.0095 & 0.08265 & 0.0009 & 511.9 & 5 \\
\hline SL1u_03 & 0.66548 & 0.0096 & 0.08215 & 0.0009 & 509 & 5 \\
\hline SL1u_04 & 0.68775 & 0.0105 & 0.08635 & 0.0009 & 533.9 & 6 \\
\hline SL1u_05 & 0.67741 & 0.0196 & 0.08371 & 0.0012 & 518.3 & 7 \\
\hline SL1u_06 & 0.70231 & 0.0128 & 0.08794 & 0.0010 & 543.4 & 6 \\
\hline SL1u_07 & 0.72313 & 0.0127 & 0.08796 & 0.0010 & 543.5 & 6 \\
\hline SL1u_08 & 0.70412 & 0.0124 & 0.08756 & 0.0010 & 541.1 & 6 \\
\hline SL1u_09 & 0.70172 & 0.0126 & 0.08616 & 0.0010 & 532.8 & 6 \\
\hline SL1u_10 & 0.69688 & 0.0128 & 0.08493 & 0.0010 & 525.5 & 6 \\
\hline SL1u_11 & 0.69829 & 0.0133 & 0.08736 & 0.0010 & 539.9 & 6 \\
\hline \multicolumn{7}{|c|}{$\begin{array}{l}\text { Unannealed half }(\mathrm{u}) \text { weighted mean age and } 95 \% \text { confidence } \\
\qquad 528 \pm 9 \mathrm{Ma}(n=11, \mathrm{MSWD}=22)\end{array}$} \\
\hline SL1a_01 & 0.65196 & 0.0094 & 0.08144 & 0.0009 & 504.7 & 5 \\
\hline SL1a_02 & 0.66218 & 0.0097 & 0.08288 & 0.0009 & 513.3 & 5 \\
\hline SL1a_03 & 0.65626 & 0.0098 & 0.08246 & 0.0009 & 510.8 & 5 \\
\hline SL1a_04 & 0.65840 & 0.0100 & 0.08242 & 0.0009 & 510.5 & 5 \\
\hline SL1a_05 & 0.67128 & 0.0106 & 0.08305 & 0.0009 & 514.3 & 5 \\
\hline SL1a_06 & 0.69062 & 0.0125 & 0.08608 & 0.0010 & 532.3 & 6 \\
\hline SL1a_07 & 0.68726 & 0.0123 & 0.08667 & 0.0010 & 535.8 & 6 \\
\hline SL1a_08 & 0.67132 & 0.0117 & 0.08431 & 0.0010 & 521.8 & 6 \\
\hline SL1a_09 & 0.68369 & 0.0124 & 0.08582 & 0.0010 & 530.8 & 6 \\
\hline SL1a_10 & 0.67936 & 0.0126 & 0.08466 & 0.0010 & 523.9 & 6 \\
\hline SL1a_11 & 0.68950 & 0.0133 & 0.08637 & 0.0010 & 534 & 6 \\
\hline \multicolumn{7}{|c|}{$\begin{array}{l}\text { Annealed half (a) weighted mean age and } 95 \% \text { confidence } \\
520 \pm 7 \mathrm{Ma}(n=11, \mathrm{MSWD}=16)\end{array}$} \\
\hline \multicolumn{7}{|c|}{$\begin{array}{l}\text { Both SL1 halves weighted mean age and 95\% confidence } \\
\qquad 524 \pm 6 \mathrm{Ma}(n=22, \mathrm{MSWD}=20)\end{array}$} \\
\hline
\end{tabular}


Table A4. U-Pb isotope ratios and ${ }^{206} \mathrm{~Pb} /{ }^{238} \mathrm{U}$ ages of the large, heterogeneous Sri Lankan zircon crystal SL2 with multiple analyses spots on both, the radiation damage-affected unannealed half $(\mathrm{u})$ and the heat-treated, annealed half (a) with its crystallinity recovered.

\begin{tabular}{|c|c|c|c|c|c|c|}
\hline \multirow{2}{*}{$\begin{array}{l}\text { Analysis } \\
\text { Spot }\end{array}$} & \multicolumn{4}{|c|}{ Isotope Ratios } & \multicolumn{2}{|c|}{ Ages [Ma] } \\
\hline & ${ }^{207} \mathrm{~Pb} /{ }^{235} \mathrm{U}$ & $\pm 2 \sigma$ & ${ }^{206} \mathrm{~Pb} /{ }^{238} \mathrm{U}$ & $\pm 2 \sigma$ & ${ }^{206} \mathrm{~Pb} /{ }^{238} \mathrm{U}$ & $\pm 2 \sigma$ \\
\hline SL2u_1 & 1.14580 & 0.0276 & 0.09145 & 0.0012 & 564.1 & 7 \\
\hline SL2u_2 & 0.74978 & 0.0187 & 0.08678 & 0.0012 & 536.5 & 7 \\
\hline SL2u_3 & 0.71283 & 0.0190 & 0.08556 & 0.0012 & 529.2 & 7 \\
\hline SL2u_4 & 0.66528 & 0.0179 & 0.08574 & 0.0012 & 530.3 & 7 \\
\hline SL2u_5 & 0.63846 & 0.0224 & 0.08431 & 0.0014 & 521.8 & 8 \\
\hline SL2u_6 & 0.64443 & 0.0194 & 0.08452 & 0.0012 & 523.1 & 7 \\
\hline SL2u_7 & 0.64826 & 0.0189 & 0.08441 & 0.0012 & 522.4 & 7 \\
\hline SL2u_8 & 0.64051 & 0.0199 & 0.08371 & 0.0012 & 518.2 & 7 \\
\hline \multicolumn{7}{|c|}{$\begin{array}{l}\text { Unannealed half }(\mathrm{u}) \text { weighted mean age and } 95 \% \text { confidence } \\
\qquad 531 \pm 12 \mathrm{Ma}(n=8, \mathrm{MSWD}=17)\end{array}$} \\
\hline SL2a_1 & 0.66047 & 0.0163 & 0.08327 & 0.0011 & 515.6 & 7 \\
\hline SL2a_2 & 0.68370 & 0.0178 & 0.08262 & 0.0011 & 511.7 & 7 \\
\hline SL2a_3 & 0.66219 & 0.0173 & 0.08324 & 0.0011 & 515.5 & 7 \\
\hline SL2a_4 & 0.64247 & 0.0170 & 0.08363 & 0.0011 & 517.8 & 7 \\
\hline SL2a_5 & 0.64947 & 0.0190 & 0.08284 & 0.0012 & 513.1 & 7 \\
\hline SL2a_6 & 0.63462 & 0.0181 & 0.08340 & 0.0012 & 516.4 & 7 \\
\hline SL2a_7 & 0.62665 & 0.0193 & 0.08211 & 0.0012 & 508.7 & 7 \\
\hline SL2a_8 & 0.62965 & 0.0196 & 0.08197 & 0.0012 & 507.9 & 7 \\
\hline \multicolumn{7}{|c|}{$\begin{array}{l}\text { Annealed half (a) weighted mean age and 95\% confidence } \\
\qquad 514 \pm 3 \mathrm{Ma}(n=8, \mathrm{MSWD}=1.1)\end{array}$} \\
\hline \multicolumn{7}{|c|}{$\begin{array}{l}\text { Both SL2 halves weighted mean age and 95\% confidence } \\
\qquad 522 \pm 7 \mathrm{Ma}(n=16, \mathrm{MSWD}=15)\end{array}$} \\
\hline
\end{tabular}


Table A5. U-Pb isotope ratios and ${ }^{206} \mathrm{~Pb} /{ }^{238} \mathrm{U}$ ages of the large, heterogeneous zircon crystal MalawiX from the Mt. Malosa Massif, Malawi with multiple analyses spots on both, the radiation damage-affected unannealed half $(\mathrm{u})$ and the heat-treated, annealed half $(\mathrm{a})$.

\begin{tabular}{|c|c|c|c|c|c|c|}
\hline \multirow{2}{*}{$\begin{array}{c}\text { Analysis } \\
\text { Spot }\end{array}$} & \multicolumn{4}{|c|}{ Isotope Ratios } & \multicolumn{2}{|c|}{ Ages [Ma] } \\
\hline & ${ }^{207} \mathrm{~Pb} /{ }^{235} \mathrm{U}$ & $\pm 2 \sigma$ & ${ }^{206} \mathrm{~Pb} /{ }^{238} \mathrm{U}$ & $\pm 2 \sigma$ & ${ }^{206} \mathrm{~Pb} /{ }^{238} \mathrm{U}$ & $\pm 2 \sigma$ \\
\hline MalawiXu_01 & 0.11931 & 0.0064 & 0.01724 & 0.0003 & 110.2 & 2 \\
\hline MalawiXu_02 & 1.28105 & 0.0332 & 0.02791 & 0.0005 & 177.5 & 3 \\
\hline MalawiXu_03 & 0.12040 & 0.0057 & 0.01786 & 0.0003 & 114.1 & 2 \\
\hline MalawiXu_04 & 0.12048 & 0.0039 & 0.01746 & 0.0003 & 111.6 & 2 \\
\hline MalawiXu_05 & 0.11512 & 0.0026 & 0.01723 & 0.0002 & 110.1 & 1 \\
\hline MalawiXu_06 & 0.13647 & 0.0125 & 0.01847 & 0.0006 & 118 & 4 \\
\hline MalawiXu_07 & 0.13201 & 0.0129 & 0.01867 & 0.0005 & 119.2 & 3 \\
\hline MalawiXu_08 & 0.64319 & 0.0299 & 0.02312 & 0.0006 & 147.3 & 4 \\
\hline MalawiXu_09 & 0.39492 & 0.0155 & 0.02027 & 0.0004 & 129.4 & 3 \\
\hline MalawiXu_10 & 0.11054 & 0.0033 & 0.01750 & 0.0003 & 111.9 & 2 \\
\hline MalawiXu_11 & 0.11505 & 0.0106 & 0.01755 & 0.0005 & 112.2 & 3 \\
\hline MalawiXu_12 & 0.11067 & 0.0042 & 0.01768 & 0.0003 & 113 & 2 \\
\hline MalawiXu_13 & 0.10788 & 0.0040 & 0.01752 & 0.0003 & 112 & 2 \\
\hline \multicolumn{7}{|c|}{ Unannealed half $(\mathrm{u})$ weighted mean age and $95 \%$ confidence } \\
\hline \multicolumn{7}{|c|}{$112 \pm 1.3 \mathrm{Ma}(n=9, \mathrm{MSWD}=3.4)$} \\
\hline 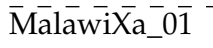 & $\overline{0} . \overline{1} 1 \overline{7} \overline{86}$ & $\overline{0} . \overline{0} 0 \overline{4} \overline{8}$ & $\overline{0.01719}-$ & $\overline{0.0003}$ & $\overline{1} 0 \overline{9} . \overline{9}$ & 2 \\
\hline MalawiXa_02 & 0.56436 & 0.0187 & 0.02105 & 0.0004 & 134.3 & 3 \\
\hline MalawiXa_03 & 0.12354 & 0.0059 & 0.01768 & 0.0003 & 113 & 2 \\
\hline MalawiXa_04 & 0.11648 & 0.0034 & 0.01718 & 0.0002 & 109.8 & 1 \\
\hline MalawiXa_05 & 0.11360 & 0.0025 & 0.01674 & 0.0002 & 107 & 1 \\
\hline MalawiXa_06 & 0.11761 & 0.0062 & 0.01762 & 0.0003 & 112.6 & 2 \\
\hline MalawiXa_07 & 0.96149 & 0.0429 & 0.02496 & 0.0008 & 158.9 & 5 \\
\hline MalawiXa_08 & 0.47604 & 0.0181 & 0.02046 & 0.0004 & 130.6 & 3 \\
\hline MalawiXa_09 & 0.20788 & 0.0105 & 0.01869 & 0.0004 & 119.4 & 3 \\
\hline MalawiXa_10 & 0.11153 & 0.0034 & 0.01736 & 0.0003 & 111 & 2 \\
\hline MalawiXa_11 & 0.10686 & 0.0091 & 0.01774 & 0.0005 & 113.3 & 3 \\
\hline MalawiXa_12 & 0.11335 & 0.0043 & 0.01721 & 0.0003 & 110 & 2 \\
\hline MalawiXa_13 & 0.10592 & 0.0038 & 0.01719 & 0.0003 & 109.8 & 2 \\
\hline
\end{tabular}

Annealed half (a) weighted mean age and 95\% confidence $110 \pm 1.6 \mathrm{Ma}(n=9, \mathrm{MSWD}=5.4)$

Both halves weighted mean age and 95\% confidence $111 \pm 1 \mathrm{Ma}(n=18, \mathrm{MSWD}=5.2)$

Notes: Measurement spots with discordant isotopic ratios within $\pm 2 \sigma$ are written in grey-colour and were not considered for calculation of the weighted mean ${ }^{206} \mathrm{~Pb} /{ }^{238} \mathrm{U}$ age. 
Table A6. U-Pb isotope ratios and ${ }^{206} \mathrm{~Pb} /{ }^{238} \mathrm{U}$ ages of the large, heterogeneous zircon crystal MalawiA from the Mt. Malosa Massif, Malawi with multiple analyses spots on both, the radiation damage-affected unannealed half $(\mathrm{u})$ and the heat-treated annealed half $(\mathrm{a})$.

\begin{tabular}{|c|c|c|c|c|c|c|}
\hline \multirow{2}{*}{$\begin{array}{c}\text { Analysis } \\
\text { Spot }\end{array}$} & \multicolumn{4}{|c|}{ Isotope Ratios } & \multicolumn{2}{|c|}{ Ages [Ma] } \\
\hline & ${ }^{207} \mathrm{~Pb} /{ }^{235} \mathrm{U}$ & $\pm 2 \sigma$ & ${ }^{206} \mathrm{~Pb} /{ }^{238} \mathrm{U}$ & $\pm 2 \sigma$ & ${ }^{206} \mathrm{~Pb} /{ }^{238} \mathrm{U}$ & $\pm 2 \sigma$ \\
\hline MalawiAu_1 & 0.29315 & 0.0171 & 0.01915 & 0.0005 & 122.3 & 3 \\
\hline MalawiAu_2 & 0.12101 & 0.0108 & 0.01715 & 0.0005 & 109.6 & 3 \\
\hline MalawiAu_3 & 0.25611 & 0.0164 & 0.01857 & 0.0005 & 118.6 & 3 \\
\hline MalawiAu_4 & 0.20370 & 0.0143 & 0.01885 & 0.0005 & 120.4 & 3 \\
\hline MalawiAu_5 & 1.70162 & 0.0543 & 0.03181 & 0.0008 & 201.8 & 5 \\
\hline MalawiAu_6 & 0.13262 & 0.0102 & 0.01797 & 0.0005 & 114.8 & 3 \\
\hline MalawiAu_7 & 0.15708 & 0.0113 & 0.01784 & 0.0005 & 114 & 3 \\
\hline 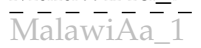 & $\overline{0} . \overline{2} 2 \overline{4} \overline{4}-$ & $\overline{0} . \overline{0} \overline{2} \overline{6}$ & $\overline{0.0 \overline{1}} \overline{90} \overline{0}$ & $\overline{0.000 \overline{0}}$ & $\overline{1} 2 \overline{1} . \overline{4}$ & -3 \\
\hline MalawiAa_2 & 0.19624 & 0.0133 & 0.01791 & 0.0005 & 114.4 & 3 \\
\hline MalawiAa_3 & 0.17784 & 0.0129 & 0.01756 & 0.0005 & 112.2 & 3 \\
\hline MalawiAa_4 & 0.25748 & 0.0156 & 0.01898 & 0.0005 & 121.2 & 3 \\
\hline MalawiAa_5 & 1.97138 & 0.0592 & 0.03390 & 0.0008 & 214.9 & 5 \\
\hline MalawiAa_6 & 0.28709 & 0.0153 & 0.01926 & 0.0005 & 123 & 3 \\
\hline MalawiAa_7 & 0.55253 & 0.0245 & 0.02151 & 0.0006 & 137.2 & 4 \\
\hline
\end{tabular}

Notes: Isotopic ratios obtained from a number of measurement spots were found to be discordant within $\pm 2 \sigma$ (written in grey-colour). Calculation of mean weighted ${ }^{206} \mathrm{~Pb} /{ }^{238} \mathrm{U}$ ages is therefore considered misleading for this sample. The age of this sample was inferred from the lower intercept of the discordia 112.3 $\pm 1.6 \mathrm{Ma}$ (see Figure 7b). 
Table A7. Trace-element concentrations from multiple spot measurements on zircon sample MalawiX from Mt. Malosa, Malawi as obtained by LA-ICP-MS (given in ppm, except for Hf and REE totals that are given in wt. \%; totals of REEs comprise Y + La to Lu). Note, that measurement spots for trace-elements differ from those chosen for U-Pb isotopic dating (Table A5 and Figure 7a). Spot locations are indicated in a PL hyperspectral map with the integrated intensity of the Dy ${ }^{3+}$ signal given color-coded.

\begin{tabular}{|c|c|c|c|c|c|c|c|c|c|c|c|c|c|c|c|c|}
\hline \multicolumn{15}{|c|}{ Element Concentrations [ppm] } & \multirow[b]{2}{*}{ - Zir Malatir-X PL473-Dy Map-50x_1 } & \\
\hline Spot: & 1 & 2 & 3 & 4 & 5 & 6 & 7 & 8 & 9 & 10 & 11 & 12 & 13 & 14 & & \\
\hline Hf & 1.22 & 1.29 & 1.32 & 0.98 & 1.00 & 1.07 & 1.06 & 0.45 & 0.44 & 0.44 & 1.02 & 1.00 & 0.99 & 0.97 & & \\
\hline $\mathbf{P}$ & 1654 & 1528 & 1533 & 2083 & 1170 & 1002 & 942 & 377 & 395 & 388 & 992 & 838 & 982 & 933 & & \\
\hline $\mathrm{Ca}$ & $<51$ & $<43$ & $<43$ & 823 & 259 & $<45$ & $<41$ & $<46$ & 59 & $<46$ & 160 & $<46$ & 49 & $<46$ & & \\
\hline $\mathrm{Ti}$ & 2 & 2 & 1 & 63 & 24 & 6 & 5 & 5 & 6 & 5 & 11 & 10 & 4 & 6 & & \\
\hline $\mathrm{Fe}$ & 275 & 496 & 321 & 5612 & 7886 & 711 & 369 & 333 & 282 & 229 & 10938 & 2016 & 154 & 172 & & \\
\hline $\mathrm{Nb}$ & 750 & 857 & 881 & 2311 & 1187 & 924 & 958 & 413 & 424 & 399 & 425 & 1014 & 734 & 835 & & \\
\hline $\mathrm{Ta}$ & 273 & 355 & 398 & 44 & 44 & 73 & 73 & 63 & 62 & 63 & 17 & 56 & 54 & 50 & & \\
\hline$\overline{\mathbf{P} \overline{\mathbf{b}}}$ & $2 \overline{7}$ & $\overline{29}^{-}$ & 30 & $\overline{18}^{-}$ & $-\overline{2} \overline{1}-$ & $-\overline{15}^{-}$ & $-\overline{14}$ & ${ }^{-} 3 \overline{0} 7^{-}$ & $\overline{29} \overline{4}$ & $\overline{3} \overline{3} 0^{-}$ & $-\overline{2} 2$ & $-\overline{1}^{-}$ & $-\overline{17}$ & $-{ }^{-} \overline{0}^{-}$ & & \\
\hline Th & 5522 & 8648 & 9948 & 16,946 & 15,496 & 15,408 & 13,449 & 5438 & 5202 & 5811 & 7222 & 15,230 & 17,873 & 21,653 & & \\
\hline $\mathbf{U}$ & 382 & 412 & 434 & 220 & 252 & 205 & 205 & 4492 & 4330 & 4842 & 161 & 253 & 255 & 303 & & \\
\hline $\bar{Y}$ & $-2 \overline{0}, \overline{04} \overline{5}$ & $\overline{19}, \overline{6} \overline{67} 7^{-}$ & $\overline{1} \overline{9}, \overline{56} \overline{1}$ & $\overline{9} \overline{67} \overline{0}$ & $\overline{10}, \overline{00} 2$ & 22,853 & $\overline{2} \overline{2}, \overline{7} \overline{7}$ & $\overline{13}, \overline{3} 0 \overline{0}$ & $\overline{1} \overline{3}, 2 \overline{7} \overline{6}$ & $\overline{13}, \overline{3} 0 \overline{8}$ & $\overline{1} \overline{4}, 0 \overline{8} 4$ & $2 \overline{3}, \overline{1} 8 \overline{7}$ & $\overline{2} 2,6 \overline{4} 9$ & $2 \overline{3}, \overline{8} 6 \overline{1}$ & & \\
\hline La & 1 & 0 & 1 & 376 & 67 & 1 & 0 & 0 & 0 & 0 & 7 & 5 & 0 & 0 & & $\Xi$ \\
\hline $\mathrm{Ce}$ & 318 & 285 & 280 & 181 & 152 & 524 & 550 & 226 & 232 & 241 & 237 & 621 & 615 & 698 & & త \\
\hline $\operatorname{Pr}$ & 0 & 0 & 1 & 62 & 14 & 3 & 2 & 1 & 1 & 2 & 3 & 5 & 3 & 6 & & ल् \\
\hline Nd & 5 & 4 & 8 & 240 & 67 & 67 & 55 & 26 & 25 & 31 & 30 & 83 & 75 & 120 & & I \\
\hline Sm & 19 & 22 & 25 & 107 & 76 & 252 & 230 & 96 & 93 & 106 & 104 & 288 & 287 & 379 & & 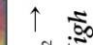 \\
\hline Eu & 4 & 5 & 5 & 13 & 12 & 43 & 41 & 17 & 16 & 18 & 19 & 49 & 49 & 62 & & \\
\hline Gd & 172 & 192 & 202 & 363 & 372 & 1356 & 1298 & 627 & 621 & 665 & 578 & 1437 & 1475 & 1724 & & 圭 \\
\hline $\mathrm{Tb}$ & 93 & 96 & 99 & 104 & 112 & 372 & 363 & 196 & 194 & 204 & 177 & 386 & 391 & 429 & & \\
\hline Dy & 1443 & 1434 & 1441 & 1055 & 1125 & 3287 & 3266 & 2007 & 1989 & 2065 & 1746 & 3361 & 3384 & 3540 & & s \\
\hline Ho & 567 & 552 & 550 & 299 & 314 & 774 & 769 & 514 & 509 & 522 & 469 & 781 & 769 & 783 & & \\
\hline Er & 2879 & 2744 & 2716 & 1142 & 1207 & 2447 & 2474 & 1587 & 1579 & 1584 & 1759 & 2474 & 2377 & 2403 & & \\
\hline $\mathrm{Tm}$ & 618 & 586 & 582 & 195 & 205 & 361 & 368 & 211 & 209 & 205 & 306 & 365 & 347 & 343 & & छ્ّ \\
\hline $\mathrm{Yb}$ & 4771 & 4488 & 4528 & 1315 & 1409 & 2195 & 2259 & 1130 & 1121 & 1068 & 2165 & 2228 & 2099 & 2051 & & 总 \\
\hline Lu & 530 & 506 & 512 & 142 & 155 & 217 & 223 & 100 & 100 & 94 & 244 & 223 & 201 & 196 & & 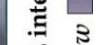 \\
\hline $\begin{array}{c}\bar{R} E \bar{E} \bar{S}^{-} \\
{[w t \%]}\end{array}$ & 3.15 & 3.06 & 3.05 & 1.53 & 1.53 & 3.47 & 3.46 & 2.04 & 1.99 & 2.01 & 2.19 & 3.55 & 3.47 & 3.66 & & \\
\hline
\end{tabular}


Table A8. Trace-element concentrations from multiple spot measurements on zircon sample MalawiA from Mt. Malosa, Malawi as obtained by LA-ICP-MS (given in ppm, except for Hf and REE totals that are given in wt.-\%; totals of REEs comprise Y + La to Lu). Note, that measurement spots for trace-elements differ from those chosen for U-Pb isotopic dating (Table A6 and Figure 7a). Spot locations are indicated in a PL hyperspectral map with the integrated intensity of the Dy ${ }^{3+}$ signal given color-coded.

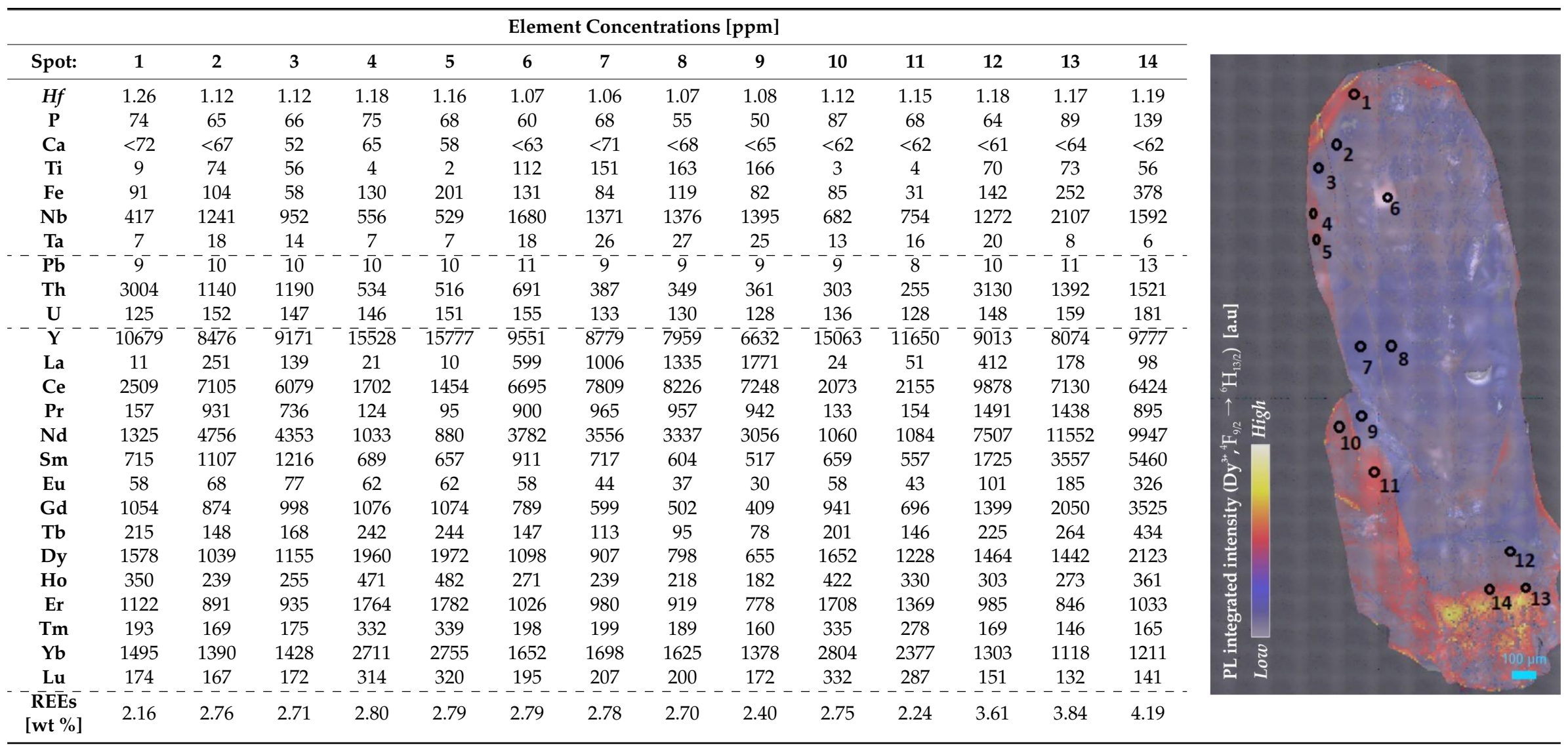


Table A9. Trace-element concentrations from multiple spot measurements on zircon sample SL2 from the Ratnapura district, Sri Lanka, as obtained by LA-ICP-MS. Concentrations given in ppm, except for Hf that are given in wt.- $\%$. Totals of REEs comprise $Y+$ La to Lu. Note, that measurement spots for trace-elements differ from those chosen for U-Pb isotopic dating (Table A4, Figure 4).

\begin{tabular}{|c|c|c|c|c|c|c|c|c|c|c|c|c|c|}
\hline \multicolumn{14}{|c|}{ Element Concentrations [ppm] } \\
\hline Spot: & 1 & 2 & 3 & 4 & 5 & 6 & 7 & 8 & 9 & 10 & 11 & 12 & 13 \\
\hline Hf & 0.79 & 0.78 & 0.80 & 0.63 & 0.62 & 0.64 & 0.64 & 0.78 & 0.75 & 0.72 & 0.98 & 0.70 & 0.80 \\
\hline $\mathbf{P}$ & 30 & 33 & 25 & 42 & 41 & 44 & 47 & 47 & 76 & 34 & 46 & 43 & 27 \\
\hline $\mathrm{Ca}$ & $<55$ & $<58$ & $<60$ & $<57$ & $<59$ & $<56$ & $<55$ & $<59$ & $<66$ & $<57$ & $<66$ & $<70$ & $<60$ \\
\hline $\mathbf{T i}$ & 4.7 & 4.3 & 4.5 & 6.3 & 6.1 & 5.1 & 5.2 & 7.8 & 24.0 & 6.7 & 4.8 & 5.6 & 5.5 \\
\hline $\mathrm{Fe}$ & $<2$ & $<2$ & $<2$ & $<2$ & $<2$ & $<2$ & $<2$ & $<2$ & $<2$ & 47 & 47 & 7 & $<3$ \\
\hline $\mathrm{Nb}$ & 0.6 & 0.6 & 0.4 & 0.7 & 0.7 & 0.8 & 0.8 & 0.8 & 1.7 & 0.5 & 0.4 & 0.5 & 0.6 \\
\hline Ta & 0.1 & 0.1 & 0.1 & 0.6 & 0.5 & 0.5 & 0.4 & 0.4 & 0.4 & 0.1 & 0.0 & 0.2 & 0.2 \\
\hline $\mathbf{P b}$ & $\overline{1} 6 \overline{1}$ & $\overline{1} 6 \overline{0}$ & $\overline{1} 6 \overline{1}$ & $\overline{17} \overline{8}$ & $16 \overline{9}$ & $2 \overline{2} \overline{7}$ & $\overline{22} \overline{5}$ & $2 \overline{2} \overline{0}$ & $1 \overline{5} \overline{6}$ & $2 \overline{1} \overline{1}$ & $\overline{6} 6^{-}$ & $2 \overline{7} 3^{-}$ & $10 \overline{0}$ \\
\hline Th & 158 & 171 & 132 & 164 & 152 & 204 & 204 & 243 & 176 & 325 & 37 & 452 & 66 \\
\hline $\mathbf{U}$ & 498 & 492 & 500 & 541 & 515 & 691 & 675 & 667 & 483 & 663 & 206 & 843 & 323 \\
\hline $\bar{Y}$ & $\overline{4} 5 \overline{9}$ & $\overline{4} 7 \overline{5}$ & $\overline{4} 4 \overline{9}-$ & $\overline{12} \overline{8}$ & $\overline{1} 1 \overline{7}$ & $\overline{150}$ & $-\overline{150}$ & $\overline{15} \overline{6}$ & $\overline{49} 0^{-}$ & $5 \overline{1} \overline{4}$ & $-\overline{85}$ & $-5 \overline{3} 0^{-}$ & $-\overline{87}--$ \\
\hline La & b.d. & b.d. & 0.003 & 0.09 & b.d. & 0.005 & 0.005 & 0.002 & 0.38 & 0.04 & 0.01 & 0.03 & 0.005 \\
\hline $\mathrm{Ce}$ & 2.4 & 2.5 & 2.2 & 1.7 & 1.7 & 2.2 & 2.2 & 2.2 & 157.4 & 2.3 & 3.7 & 2.3 & 2.1 \\
\hline $\operatorname{Pr}$ & b.d. & 0.02 & 0.03 & 0.02 & b.d. & 0.02 & 0.01 & 0.01 & 0.24 & 0.08 & b.d. & 0.09 & b.d. \\
\hline $\mathrm{Nd}$ & 0.3 & 0.4 & 0.4 & 0.2 & 0.2 & 0.4 & 0.1 & 0.3 & 1.9 & 1.4 & b.d. & 1.5 & 0.1 \\
\hline Sm & 1.1 & 1.1 & 0.9 & 0.4 & 0.3 & 0.5 & 0.6 & 0.6 & 1.6 & 2.7 & 0.2 & 2.9 & 0.3 \\
\hline Eu & 0.3 & 0.4 & 0.3 & 0.1 & 0.1 & 0.1 & 0.2 & 0.2 & 1.1 & 0.8 & 0.1 & 0.6 & 0.1 \\
\hline Gd & 6.8 & 6.8 & 6.7 & 1.8 & 1.8 & 2.7 & 2.3 & 2.9 & 9.1 & 10.4 & 0.9 & 10.9 & 1.1 \\
\hline $\mathbf{T b}$ & 2.3 & 2.4 & 2.3 & 0.7 & 0.6 & 0.8 & 0.8 & 0.8 & 2.8 & 3.1 & 0.4 & 3.2 & 0.4 \\
\hline Dy & 32 & 33 & 30 & 9 & 8 & 10 & 10 & 11 & 37 & 40 & 5 & 41 & 6 \\
\hline Ho & 13 & 14 & 13 & 4 & 3 & 4 & 4 & 5 & 15 & 15 & 2 & 16 & 3 \\
\hline Er & 73 & 74 & 71 & 20 & 19 & 23 & 23 & 24 & 75 & 80 & 14 & 82 & 14 \\
\hline $\mathrm{Tm}$ & 18 & 18 & 18 & 5 & 5 & 6 & 6 & 6 & 19 & 19 & 4 & 20 & 4 \\
\hline $\mathbf{Y b}$ & 188 & 193 & 186 & 55 & 52 & 64 & 61 & 66 & 195 & 199 & 44 & 204 & 40 \\
\hline $\mathbf{L u}$ & 33 & 34 & 32 & 10 & 10 & 11 & 11 & 12 & 34 & 35 & 9 & 36 & 7 \\
\hline $55^{-}-1$ & & & & $\overline{-5} \overline{-}$ & $\overline{2} 1 \overline{8}$ & $\overline{27} \overline{6}$ & 271 & $2 \overline{8} \overline{7}$ & 103 & $9 \overline{2} 2$ & $1 \overline{6} 8$ & 950 & $1 \overline{6} 4^{-}$ \\
\hline
\end{tabular}

\section{References}

1. Pabst, A. The metamict state. Am. Mineral. J. Earth Planet. Mater. 1952, 37, 137-157.

2. Ewing, R.C. The metamict state: 1993-The centennial. Nucl. Instrum. Methods Phys. Res. Sect. B Beam Interact. Mater. At. 1994, 91, 22-29. [CrossRef]

3. Nasdala, L.; Grambole, D.; Ruschel, K. Review of effects of radiation damage on the luminescence emission of minerals, and the example of He-irradiated $\mathrm{CePO}_{4}$. Mineral. Petrol. 2013, 107, 441-454. [CrossRef]

4. Weber, W.J. Radiation-induced defects and amorphization in zircon. J. Mater. Res. 1990, 5, $2687-2697$. [CrossRef]

5. Trachenko, K.O.; Dove, M.T.; Salje, E.K. Atomistic modelling of radiation damage in zircon. J. Phys. Condens. Matter 2001, 13, 1947. [CrossRef]

6. Holland, H.D.; Gottfried, D. The effect of nuclear radiation on the structure of zircon. Acta Crystallogr. 1955, 8, 291-300. [CrossRef]

7. Chakoumakos, B.C.; Oliver, W.C.; Lumpkin, G.R.; Ewing, R.C. Hardness and elastic modulus of zircon as a function of heavy-particle irradiation dose: I. In situ $\alpha$-decay event damage. Radiat. Eff. Defects Solids 1991, 118, 393-403. [CrossRef]

8. Palenik, C.S.; Nasdala, L.; Ewing, R.C. Radiation damage in zircon. Am. Mineral. 2003, 88, 770-781. [CrossRef]

9. Beirau, T.; Nix, W.D.; Pöllmann, H.; Ewing, R.C. Radiation-induced effects on the mechanical properties of natural $\mathrm{ZrSiO}_{4}$ : Double cascade-overlap damage accumulation. Phys. Chem. Miner. 2018, 45, 435-442. [CrossRef]

10. Balan, E.; Neuville, D.R.; Trocellier, P.; Fritsch, E.; Muller, J.-P.; Calas, G. Metamictization and chemical durability of detrital zircon. Am. Mineral. 2001, 86, 1025-1033. [CrossRef] 
11. Mathieu, R.; Zetterström, L.; Cuney, M.; Gauthier-Lafaye, F.; Hidaka, H. Alteration of monazite and zircon and lead migration as geochemical tracers of fluid paleocirculations around the Oklo-Okélobondo and Bangombé natural nuclear reaction zones (Franceville basin, Gabon). Chem. Geol. 2001, 171, 147-171. [CrossRef]

12. Geisler, T.; Trachenko, K.; Ríos, S.; Dove, M.T.; Salje, E.K. Impact of self-irradiation damage on the aqueous durability of zircon $\left(\mathrm{ZrSiO}_{4}\right)$ : Implications for its suitability as a nuclear waste form. J. Phys. Condens. Matter 2003, 15, L597-L605. [CrossRef]

13. Geisler, T.; Pidgeon, R.T.; Kurtz, R.; Van Bronswijk, W.; Schleicher, H. Experimental hydrothermal alteration of partially metamict zircon. Am. Mineral. 2003, 88, 1496-1513. [CrossRef]

14. Kuiper, Y.D. Isotopic age constraints from electron microprobe U-Th-Pb dates, using a three-dimensional concordia diagram. Am. Mineral. 2005, 90, 586-591. [CrossRef]

15. Zamyatin, D.A.; Shchapova, Y.V.; Votyakov, S.L.; Nasdala, L.; Lenz, C. Alteration and chemical U-Th-total Pb dating of heterogeneous high-uranium zircon from a pegmatite from the Aduiskii Massif, Middle Urals, Russia. Mineral. Petrol. 2017, 111, 475-497. [CrossRef]

16. Lumpkin, G.R. Ceramic waste forms for actinides. Elements 2006, 2, 365-372. [CrossRef]

17. Lumpkin, G.R. Ceramic host phases for nuclear waste remediation. In Experimental and Theoretical Approaches to Actinide Chemistry; Gibson, J.K., de Jong, W.A., Eds.; John Wiley \& Sons: Hoboken, NJ, USA, 2018.

18. Weber, W.J.; Ewing, R.C.; Catlow, C.R.A.; De La Rubia, T.D.; Hobbs, L.W.; Kinoshita, C.; Matzke, H.; Motta, A.T.; Nastasi, M.; Salje, E.K.H. Radiation effects in crystalline ceramics for the immobilization of high-level nuclear waste and plutonium. J. Mater. Res. 1998, 13, 1434-1484. [CrossRef]

19. Ewing, R.C. The design and evaluation of nuclear-waste forms: Clues from mineralogy. Can. Mineral. 2001, 39, 697-715. [CrossRef]

20. Chakoumakos, B.C.; Murakami, T.; Lumpkin, G.R.; Ewing, R.C. Alpha-decay-induced fracturing in zircon: The transition from the crystalline to the metamict state. Science 1987, 236, 1556-1559. [CrossRef]

21. Sláma, J.; Košler, J.; Condon, D.J.; Crowley, J.L.; Gerdes, A.; Hanchar, J.M.; Horstwood, M.S.; Morris, G.A.; Nasdala, L.; Norberg, N. Plešovice zircon-A new natural reference material for $\mathrm{U}-\mathrm{Pb}$ and $\mathrm{Hf}$ isotopic microanalysis. Chem. Geol. 2008, 249, 1-35. [CrossRef]

22. Nasdala, L.; Wenzel, M.; Vavra, G.; Irmer, G.; Wenzel, T.; Kober, B. Metamictisation of natural zircon: Accumulation versus thermal annealing of radioactivity-induced damage. Contrib. Mineral. Petrol. 2001, 141, 125-144. [CrossRef]

23. Nasdala, L.; Hanchar, J.M.; Rhede, D.; Kennedy, A.K.; Váczi, T. Retention of uranium in complexly altered zircon: An example from Bancroft, Ontario. Chem. Geol. 2010, 269, 290-300. [CrossRef]

24. Yada, K.; Tanji, T.; Sunagawa, I. Application of lattice imagery to radiation damage investigation in natural zircon. Phys. Chem. Miner. 1981, 7, 47-52. [CrossRef]

25. Murakami, T.; Chakoumakos, B.C.; Ewing, R.C.; Lumpkin, G.R.; Weber, W.J. Alpha-decay event damage in zircon. Am. Mineral. 1991, 76, 1510-1532.

26. Weber, W.J.; Ewing, R.C.; Wang, L.-M. The radiation-induced crystalline-to-amorphous transition in zircon. J. Mater. Res. 1994, 9, 688-698. [CrossRef]

27. Lumpkin, G.R.; Smith, K.L.; Gieré, R. Application of analytical electron microscopy to the study of radiation damage in the complex oxide mineral zirconolite. Micron 1997, 28, 57-68. [CrossRef]

28. Meldrum, A.; Boatner, L.A.; Weber, W.J.; Ewing, R.C. Radiation damage in zircon and monazite. Geochim. Cosmochim. Acta 1998, 62, 2509-2520. [CrossRef]

29. Ewing, R.C. Nuclear waste forms for actinides. Proc. Natl. Acad. Sci. USA 1999, 96, 3432-3439. [CrossRef]

30. Capitani, G.C.; Leroux, H.; Doukhan, J.C.; Ríos, S.; Zhang, M.; Salje, E.K.H. A TEM investigation of natural metamict zircons: Structure and recovery of amorphous domains. Phys. Chem. Miner. 2000, 27, 545-556. [CrossRef]

31. Nasdala, L.; Lengauer, C.L.; Hanchar, J.M.; Kronz, A.; Wirth, R.; Blanc, P.; Kennedy, A.K.; Seydoux-Guillaume, A.-M. Annealing radiation damage and the recovery of cathodoluminescence. Chem. Geol. 2002, 191, 121-140. [CrossRef]

32. Nasdala, L.; Reiners, P.W.; Garver, J.I.; Kennedy, A.K.; Stern, R.A.; Balan, E.; Wirth, R. Incomplete retention of radiation damage in zircon from Sri Lanka. Am. Mineral. 2004, 89, 219-231. [CrossRef]

33. Ríos, S.; Salje, E.K.; Zhang, M.; Ewing, R.C. Amorphization in zircon: Evidence for direct impact damage. J. Phys.: Condens. Matter 2000, 12, 2401. [CrossRef] 
34. Park, S.; Lang, M.; Tracy, C.L.; Zhang, J.; Zhang, F.; Trautmann, C.; Kluth, P.; Rodriguez, M.D.; Ewing, R.C. Swift heavy ion irradiation-induced amorphization of $\mathrm{La}_{2} \mathrm{Ti}_{2} \mathrm{O}_{7}$. Nucl. Instrum. Methods Phys. Res. Sect. B Beam Interact. Mater. At. 2014, 326, 145-149. [CrossRef]

35. Zhang, M.; Salje, E.K. Infrared spectroscopic analysis of zircon: Radiation damage and the metamict state. J. Phys. Condens. Matter 2001, 13, 3057. [CrossRef]

36. Farnan, I.; Salje, E.K.H. The degree and nature of radiation damage in zircon observed by ${ }^{29}$ Si nuclear magnetic resonance. J. Appl. Phys. 2001, 89, 2084-2090. [CrossRef]

37. Kinny, P.D.; Compston, W.; Williams, I.S. A reconnaissance ion-probe study of hafnium isotopes in zircons. Geochim. Cosmochim. Acta 1991, 55, 849-859. [CrossRef]

38. Pidgeon, R.T. Calibration of zircon standards for the Curtin SHRIMP II. In Proceedings of the Abstract of Eighth International Conference on Geochronology; Cosmochronology and Isotope Geology, U.S. Geological Survey: Reston, VA, USA, 1994.

39. Nasdala, L.; Hofmeister, W.; Norberg, N.; Martinson, J.M.; Corfu, F.; Dörr, W.; Kamo, S.L.; Kennedy, A.K.; Kronz, A.; Reiners, P.W. Zircon M257-A homogeneous natural reference material for the ion microprobe $\mathrm{U}-\mathrm{Pb}$ analysis of zircon. Geostand. Geoanal. Res. 2008, 32, 247-265. [CrossRef]

40. Nasdala, L.; Corfu, F.; Valley, J.W.; Spicuzza, M.J.; Wu, F.-Y.; Li, Q.-L.; Yang, Y.-H.; Fisher, C.; Münker, C.; Kennedy, A.K. Zircon M127-A homogeneous reference material for SIMS U-Pb geochronology combined with hafnium, oxygen and, potentially, lithium isotope analysis. Geostand. Geoanal. Res. 2016, 40, 457-475. [CrossRef]

41. Stern, R.A. A New Isotopic and Trace-Element Standard for the Ion Microprobe: Preliminary Thermal Ionization Mass Spectrometry (TIMS) U-Pb and Electron-Microprobe Data; Natural Resources Canada, Geological Survey of Canada: Ottawa, ON, Canada, 2001.

42. Santos, M.M.; Lana, C.; Scholz, R.; Buick, I.; Schmitz, M.D.; Kamo, S.L.; Gerdes, A.; Corfu, F.; Tapster, S.; Lancaster, P. A new appraisal of Sri Lankan BB zircon as a reference material for LA-ICP-MS U-Pb geochronology and Lu-Hf isotope tracing. Geostand. Geoanal. Res. 2017, 41, 335-358. [CrossRef]

43. Nasdala, L.; Irmer, G.; Wolf, D. The degree of metamictization in zircons: A Raman spectroscopic study. Eur. J. Mineral. 1995, 7, 471-478. [CrossRef]

44. Lenz, C.; Nasdala, L. A photoluminescence study of $\mathrm{REE}^{3+}$ emissions in radiation-damaged zircon. Am. Mineral. 2015, 100, 1123-1133. [CrossRef]

45. Nasdala, L.; Akhmadaliev, S.; Artac, A.; Chanmuang, C.; Habler, G.; Lenz, C. Irradiation effects in monazite-(Ce) and zircon: Raman and photoluminescence study of Au-irradiated FIB foils. Phys. Chem. Miner. 2018, 45, 855-871. [CrossRef] [PubMed]

46. Bau, M. Controls on the fractionation of isovalent trace elements in magmatic and aqueous systems: Evidence from $\mathrm{Y} / \mathrm{Ho}, \mathrm{Zr} / \mathrm{Hf}$, and lanthanide tetrad effect. Contrib. Mineral. Petrol. 1996, 123, 323-333. [CrossRef]

47. Nicholas, J.V. Origin of the luminescence in natural zircon. Nature 1967, 215, 1476. [CrossRef]

48. Gaft, M.; Panczer, G.; Reisfeld, R.; Shinno, I. Laser-induced luminescence of rare-earth elements in natural zircon. J. Alloy. Compd. 2000, 300, 267-274. [CrossRef]

49. Panczer, G.; De Ligny, D.; Mendoza, C.; Gaft, M.; Seydoux-Guillaume, A.M.; Wang, X. Raman and fluorescence. In Applications of Raman Spectroscopy to Earth Sciences and Cultural Heritage; Dubessy, J., Caumon, M.C., Rull, F., Eds.; EMU Notes in Mineralogy; European Mineralogical Union and Mineralogical Society of Great Britain and Ireland: London, UK, 2012; Volume 12, pp. 61-82.

50. Friis, H.; Finch, A.A.; Williams, C.T.; Hanchar, J.M. Photoluminescence of zircon $\left(\mathrm{ZrSiO}_{4}\right)$ doped with REE ${ }^{3+}$ (REE = Pr, Sm, Eu, Gd, Dy, Ho, Er). Phys. Chem. Miner. 2010, 37, 333-342. [CrossRef]

51. Lenz, C.; Nasdala, L.; Talla, D.; Hauzenberger, C.; Seitz, R.; Kolitsch, U. Laser-induced REE3 ${ }^{+}$ photoluminescence of selected accessory minerals-An "advantageous artefact" in Raman spectroscopy. Chem. Geol. 2015, 415, 1-16. [CrossRef]

52. Lenz, C.; Talla, D.; Ruschel, K.; Škoda, R.; Götze, J.; Nasdala, L. Factors affecting the $\mathrm{Nd}^{3+}\left(\mathrm{REE}^{3+}\right)$ luminescence of minerals. Mineral. Petrol. 2013, 107, 415-428. [CrossRef]

53. Geisler, T.; Burakov, B.E.; Zirlin, V.; Nikolaeva, L.; Pöml, P. A Raman spectroscopic study of high-uranium zircon from the Chernobyl lava. Eur. J. Mineral. 2005, 17, 883-894. [CrossRef]

54. Kempe, U.; Seltmann, R.; Graupner, T.; Rodionov, N.; Sergeev, S.A.; Matukov, D.I.; Kremenetsky, A.A. Concordant $\mathrm{U}-\mathrm{Pb}$ SHRIMP ages of U-rich zircon in granitoids from the Muruntau gold district (Uzbekistan): Timing of intrusion, alteration ages, or meaningless numbers. Ore Geol. Rev. 2015, 65, 308-326. [CrossRef] 
55. Kempe, U.; Trinkler, M.; Pöppl, A.; Himcinschi, C. Coloration of natural zircon. Can. Mineral. 2016, 54, 635-660. [CrossRef]

56. Kempe, U.; Trullenque, G.; Thomas, R.; Sergeev, S.; Presnyakov, S.; Rodionov, N.; Himcinschi, C. Substitution-induced internal strain and high disorder in weakly radiation damaged hydrothermal zircon from Mt. Malosa, Malawi. Eur. J. Mineral. 2018, 30, 659-679. [CrossRef]

57. Ruschel, K.; Nasdala, L.; Kronz, A.; Hanchar, J.M.; Többens, D.M.; Škoda, R.; Finger, F.; Möller, A. A Raman spectroscopic study on the structural disorder of monazite-(Ce). Mineral. Petrol. 2012, 105, 41-55. [CrossRef]

58. Lenz, C.; Thorogood, G.; Aughterson, R.; Ionescu, M.; Gregg, D.J.; Davis, J.; Lumpkin, G.R. The quantification of radiation damage in orthophosphates using confocal $\mu$-luminescence spectroscopy of $\mathrm{Nd}^{3+}$. Front. Chem. 2019, 7, 13. [CrossRef] [PubMed]

59. Soman, A.; Geisler, T.; Tomaschek, F.; Grange, M.; Berndt, J. Alteration of crystalline zircon solid solutions: A case study on zircon from an alkaline pegmatite from Zomba-Malosa, Malawi. Contrib. Mineral. Petrol. 2010, 160, 909-930. [CrossRef]

60. Nasdala, L.; Kronz, A.; Hanchar, J.M.; Tichomirowa, M.; Davis, D.W.; Hofmeister, W. Effects of natural radiation damage on back-scattered electron images of single crystals of minerals. Am. Mineral. 2006, 91, 1739-1746. [CrossRef]

61. Váczi, T. A new, simple approximation for the deconvolution of instrumental broadening in spectroscopic band profiles. Appl. Spectrosc. 2014, 68, 1274-1278. [CrossRef]

62. Elhlou, S.; Belousova, E.; Griffin, W.L.; Pearson, N.J.; O’Reilly, S.Y. Trace element and isotopic composition of GJ-red zircon standard by laser ablation. Geochim. Cosmochim. Acta Suppl. 2006, 70, A158. [CrossRef]

63. Jackson, S.E.; Pearson, N.J.; Griffin, W.L.; Belousova, E.A. The application of laser ablation-inductively coupled plasma-mass spectrometry to in situ U-Pb zircon geochronology. Chem. Geol. 2004, 211, 47-69. [CrossRef]

64. Griffin, W.L.; Powell, W.J.; Pearson, N.J.; O’Reilly, S.Y. GLITTER: Data reduction software for laser ablation ICP-MS. In Laser Ablation ICP-MS in the Earth Sciences: Current Practices and Outstanding Issues; Sylvester, P., Ed.; MAC Short-Course; Mineralogical Association of Canada: Quebec City, QC, Canada, 2008; pp. 308-311.

65. Belousova, E.; Griffin, W.L.; O’Reilly, S.Y.; Fisher, N.L. Igneous zircon: Trace element composition as an indicator of source rock type. Contrib. Mineral. Petrol. 2002, 143, 602-622. [CrossRef]

66. Zeug, M.; Nasdala, L.; Wanthanachaisaeng, B.; Balmer, W.A.; Corfu, F.; Wildner, M. Blue Zircon from Ratanakiri, Cambodia. J. Gemmol. 2018, 36, 112-132. [CrossRef]

67. Nagli, L.; Bunimovich, D.; Katzir, A.; Gorodetsky, O.; Molev, V. The luminescence properties of Dy-doped high silicate glass. J. Non-Cryst. Solids 1997, 217, 208-214. [CrossRef]

68. Nasdala, L.; Götze, J.; Hanchar, J.M.; Gaft, M.; Krbetschek, M.R. Luminescence techniques in Earth sciences. In Spectroscopic Methods in Mineralogy; Beran, A., Libowitzky, E., Eds.; EMU Notes in Mineralogy; European Mineralogical Union and Mineralogical Society of Great Britain and Ireland: London, UK, 2004; Volume 6, pp. 43-91.

69. Trachenko, K.; Dove, M.T.; Salje, E.K. Large swelling and percolation in irradiated zircon. J. Phys. Condens. Matter 2002, 15, L1. [CrossRef]

70. Carnall, W.T.; Goodman, G.L.; Rajnak, K.; Rana, R.S. A systematic analysis of the spectra of the lanthanides doped into single crystal $\mathrm{LaF}_{3}$. J. Chem. Phys. 1989, 90, 3443-3457. [CrossRef]

71. Finch, A.A.; Garcia-Guinea, J.; Hole, D.E.; Townsend, P.D.; Hanchar, J.M. Ionoluminescence of zircon: Rare earth emissions and radiation damage. J. Phys. D Appl. Phys. 2004, 37, 2795. [CrossRef]

72. Steely, A.N.; Hourigan, J.K.; Juel, E. Discrete multi-pulse laser ablation depth profiling with a single-collector ICP-MS: Sub-micron U-Pb geochronology of zircon and the effect of radiation damage on depth-dependent fractionation. Chem. Geol. 2014, 372, 92-108. [CrossRef]

73. Marillo-Sialer, E.; Woodhead, J.; Hanchar, J.M.; Reddy, S.M.; Greig, A.; Hergt, J.; Kohn, B. An investigation of the laser-induced zircon 'matrix effect'. Chem. Geol. 2016, 438, 11-24. [CrossRef]

74. Wiemer, D.; Allen, C.M.; Murphy, D.T.; Kinaev, I. Effects of thermal annealing and chemical abrasion on ca. 3.5 Ga metamict zircon and evidence for natural reverse discordance: Insights for UPb LA-ICP-MS dating. Chem. Geol. 2017, 466, 285-302. [CrossRef]

75. Allen, C.M.; Campbell, I.H. Identification and elimination of a matrix-induced systematic error in LA-ICP-MS ${ }^{206} \mathrm{~Pb} /{ }^{238} \mathrm{U}$ dating of zircon. Chem. Geol. 2012, 332, 157-165. [CrossRef] 
76. Solari, L.A.; Ortega-Obregón, C.; Bernal, J.P. U-Pb zircon geochronology by LAICPMS combined with thermal annealing: Achievements in precision and accuracy on dating standard and unknown samples. Chem. Geol. 2015, 414, 109-123. [CrossRef]

77. Shnukov, S.E.; Andreev, A.V.; Savenok, S.P. Admixture elements in zircons and apatites: A tool for provenance studies of terrigenous sedimentary rocks. In Proceedings of the European Union of Geosciences 1997, Strasbourg, France, 23-27 March 1997.

78. Hoskin, P.W.O. Trace-element composition of hydrothermal zircon and the alteration of Hadean zircon from the Jack Hills, Australia. Geochim. Cosmochim. Acta 2005, 69, 637-648. [CrossRef]

79. De Hoog, J.C.M.; Lissenberg, C.J.; Brooker, R.A.; Hinton, R.; Trail, D.; Hellebrand, E. Hydrogen incorporation and charge balance in natural zircon. Geochim. Cosmochim. Acta 2014, 141, 472-486. [CrossRef]

80. Nasdala, L.; Beran, A.; Libowitzky, E.; Wolf, D. The incorporation of hydroxyl groups and molecular water in natural zircon $\left(\mathrm{ZrSiO}_{4}\right)$. Am. J. Sci. 2001, 301, 831-857. [CrossRef]

(C) 2020 by the authors. Licensee MDPI, Basel, Switzerland. This article is an open access article distributed under the terms and conditions of the Creative Commons Attribution (CC BY) license (http://creativecommons.org/licenses/by/4.0/). 